\title{
La antropología catalana y el exilio republicano español en México
}

\author{
Catalan Anthropology and the Spanish \\ Republican Exile in Mexico
}

\author{
Joan J. Pujadas ${ }^{1}$ \\ Universitat Rovira i Virgili
}

\section{RESUMEN}

Este artículo constituye una exploración preliminar, de carácter eminentemente biográfico, de un proyecto de más largo aliento que pretende analizar el impacto de la antropología mexicana en la Cataluña del último tercio del siglo XX e inicios del XXI, con especial atención a la obra de los profesionales mexicanos de las ciencias antropológicas, procedentes del exilio republicano español. Tras una primera sección dedicada a la presentación del proceso de implantación de la antropología en la Universidad de Barcelona, en torno a la figura de Claudi Esteva Fabregat, se dedica una segunda a la caracterización del entorno social e institucional en que se enmarca la llegada de los exilados a México.

Seguidamente se presenta el papel fundacional que desarrollaron Pere Bosch i Gimpera y Joan Comas i Camps, exilados en el cénit de su carrera académica. Las secciones siguientes abordan la biografía y las principales contribuciones de los exilados jóvenes que se formaron ya en México (ENAH y UNAM), procedentes de Barcelona (Ángel Palerm, Claudi Esteva y Pedro Armillas), Valencia (Santiago Genovés), de Madrid (Pedro Carrasco, José L. Lorenzo y Carmen Viqueira) y Logroño (Enrique Nalda). Todos ellos acabarán siendo figuras esenciales de la profesión en la segunda mitad del siglo XX. Junto a ellos, damos noticia de la labor de los ocho miembros de la segunda generación, hijos de exilados: Gloria Artís Espriu, Gloria Artís Mercadet, Armando Bartra, Roger Bartra, Andrés Fábregas, Jordi Gussinyer y, finalmente, Jacinta y Juan Vicente Palerm. El texto concluye presentando algunos ejemplos de las conexiones existentes en la actualidad.

Palabras clave: Exilio republicano; Ciencias antropológicas; México; Cataluña; España; Segunda generación.

\section{SUMMARY}

This article constitutes a preliminary exploration, of an eminently biographical nature, of a longer project that seeks to analyse the impact of Mexican anthropology in Catalonia in the last third of the twentieth and the beginning of the twenty-first century, with special attention to the work of professionals in the Mexican anthropological sciences, derived from the Spanish republican exile. After a first section dedicated to the presentation of the process of introducing anthropology at the University of Barcelona, around the figure of Claudi Esteva Fabregat, a second section is dedicated to the characterisation of the social and institutional environment in which the arrival of the exiles to Mexico is framed.

\footnotetext{
${ }^{1}$ Correo electrónico: joanjosep.pujadas@urv.cat. ORCID iD: http://orcid.org/0000-0001-8230-4523.
} 
This is followed by a presentation of the foundational role played by Pere Bosch i Gimpera and Joan Comas i Camps, exiled at the zenith of their academic careers. The following sections address the biography and major contributions of young exiles educated in Mexico (ENAH and UNAM), who had come from Barcelona (Angel Palerm, Claudi Esteva and Pedro Armillas), Valencia (Santiago Genovés), Madrid (Pedro Carrasco, José L. Lorenzo and Carmen Viqueira) and Logroño (Enrique Nalda). They all become essential figures in anthropology in the second half of the twentieth century. We also report on the work of eight members of the second generation who were children of exiles: Gloria Artís Espriu, Gloria Artís Mercadet, Armando Bartra, Roger Bartra, Andrés Fábregas, Jordi Gussinyer and finally Jacinta and Juan Vicente Palerm. The text concludes with examples of existing bilateral connections.

Key words: Republican Exile; Anthropological Sciences; Mexico; Catalonia; Spain; Second Generation.

Este texto sobre el exilio republicano a México tiene muchos elementos autobiográficos. Yo no soy ningún exiliado, ni mis padres o abuelos sufrieron un exilio hacia ningún país extranjero, pero tanto mi familia paterna como materna, republicanos fervientes, sufrieron un exilio interior con prisión y expolio de bienes y propiedades. No fue hasta hace unos pocos lustros cuando pude evaluar cómo este exilio interior influenció nuestras vidas a nivel familiar, personal y profesional. Por otro lado, la oportunidad de poder conocer y tratar a lo largo de los años a algunos de los protagonistas del exilio exterior ha tenido también un importante impacto profesional e identitario.

Los antropólogos y las antropólogas catalanes de mi generación tuvimos como maestro a un exiliado catalán, el Dr. Claudi Esteva, que llegó a México el año 1939 a bordo del barco Sinaia, junto con 1.800 compatriotas más. El exilio del Dr. Esteva fue doble. Un exilio mexicano en sentido estricto, que se prolongó hasta el año 1957, y un reexilio hacia España, motivado por su militancia política en el exterior, que lo situó en Madrid durante 11 años, hasta que pudo volver a su Barcelona natal.

Con mis congéneres catalanes, con Joan Prat al frente, he compartido la preocupación de establecer nuestra filiación intelectual²: de quién somos hijos, cuáles son nuestros antecedentes, nuestras raíces ${ }^{3}$. Algunos de los elementos que nos unen, generacionalmente, tienen que ver con nuestra militancia antifranquista, con un predominio del marxismo teórico e ideológico y una clara opción en aquellos años 70 por el estudio del campesinado y por aquello que en términos gramscianos eran las sociedades subalternas. Debemos tener presente que el contexto universitario en los años en que nos formamos en la Universidad de Barcelona estaba dominado por la corriente estructuralista y, en nuestro caso concreto, por los enfoques culturalistas y muy especialmente por la Escuela de Cultura y Personalidad, que era la filiación donde se enmarcaba profesional y teóricamente nuestro introductor a la antropología, el Dr. Esteva.

\footnotetext{
${ }^{2}$ Sobre el estudio de los antecedentes de la antropología social en Cataluña, cabe destacar los trabajos siguientes: Prat (1980, 1986, 1990, 1991 y 1999), Prats, Llopart y Prat (1982), Prat y Pujadas (1991), Pujadas y Prat (1981a y b), y Calvo (1991, 1994, 1996 y 1997).

${ }^{3}$ Junto a mi interés por la vida, obra y trayectoria intelectual del Dr. Ángel Palerm (Pujadas 1984, 2000 y 2014; Contreras, Pujadas y Terradas 2000), dediqué hace treinta y cinco años un ensayo a otro de nuestros exiliados, en este caso a Gran Bretaña, el Prof. Josep M. Batista i Roca (Pujadas 1980).
} 
Dicho esto para enmarcar los antecedentes y las motivaciones que están detrás de este texto, mi objetivo principal es presentar a los protagonistas de este exilio y sus conexiones, a lo largo de los años, para mostrar el impacto que sobre la antropología catalana tuvo el impulso intelectual propiciado por el exilio republicano español y, particularmente, por la obra de los exiliados republicanos vinculados a las instituciones académicas mexicanas. Mi pretensión no consiste en el análisis de la recepción en Cataluña de las investigaciones de los exiliados, intentando establecer en qué medida marcaron la agenda investigadora de nuestra generación, ya que esto constituiría en sí mismo el tema de otra investigación. Solamente pretendo presentar las trayectorias profesionales de los exiliados catalanes y de algunos miembros de la segunda generación para que sea comprensible la existencia de densas conexiones entre antropólogos y antropólogas mexicanos y españoles que llegan hasta nuestros días Una expresión muy reciente del reconocimiento hacia las contribuciones decisivas que los exiliados republicanos tuvieron para el desarrollo de la antropología en ambos lados del Atlántico es la reciente constitución de la Cátedra Ángel Palerm, que agrupa a cuatro universidades mexicanas y cuatro españolas, que se reclaman herederas y continuadoras tanto de la obra de este ibicenco universal, como del ambiente intelectual creado por la antropología del exilio en México5.

\section{EXILIO Y DESEXILIO EN EL PROCESO DE CREACIÓN DE LA ANTROPOLOGÍA EN CATALUÑA DURANTE LA TRANSICIÓN DEMOCRÁTICA (1975-1987)}

El exilio republicano estuvo presente en nuestros años de estudiantes universitarios de maneras diferentes. Casi todos los libros que constituyeron nuestras primeras lecturas de antropología estaban publicados en México (Fondo de Cultura Económi(ca) ${ }^{6}$. Claudi Esteva, después de haber cursado con él las materias introductorias de Antropología cultural y Etnología de los pueblos primitivos, nos fue ofreciendo en años sucesivos cursos monográficos sobre etnología americana: Cultura Azteca, Cultura Maya, Cultura Andina ${ }^{7}$. En el curso 1970-1971 Claudi Esteva invitó al Prof. Joan Co-

\footnotetext{
${ }^{4}$ Si bien mi punto de partida ha consistido en la selección de antropólogos y antropólogas procedentes de Cataluña y exilados a México, decidí incorporar a los tres exilados procedentes de Madrid para tener una visión más amplia de la antropología en el exilio.

${ }^{5}$ La Cátedra Ángel Palerm se constituyó en México el año 2005, para honrar la memoria de quien fue pieza fundamental en la instauración de los estudios de antropología en las cuatro instituciones mexicanas consorciadas: Universidad Autónoma Metropolitana-Iztapalapa (UAM-I), Centro de Investigación y Estudios Superiores de Antropología Social (CIESAS), Universidad Iberoamericana (UIA) y El Colegio de Michoacán (ColMich). El año 2014 se creó un consorcio de universidades catalanes y españolas, que constituyen la antena española de la mencionada cátedra: Universitat Rovira i Virgili, Universitat de Barcelona, Universidad de Sevilla y Universidad Autónoma de Madrid.

${ }^{6}$ Libros como los de los siguientes autores: Herskovits (El hombre y sus obras, 1952), Kluckhohn (Antropología, 1957), Linton (Estudio del hombre, 1961), Lévi-Strauss (El pensamiento salvaje, 1964), Lewis (Antropología de la pobreza, 1961), Sapir (El lenguaje, 1966), Swadesh (El lenguaje y la vida bumana, 1966), Soustelle (La vida cotidiana de los aztecas en vísperas de la conquista, 1970) y Caso (El pueblo del sol, 1971).

${ }^{7}$ Claudi Esteva en aquellos años de formación del grupo de antropología en la Universidad de Barcelona también ofreció un curso titulado Antropología para Lingüistas, impartido en la Licenciatura de Filología Románica.
} 
mas, exiliado como él a México (UNAM), a impartir una conferencia en nuestra facultad. Por aquel entonces otro exiliado republicano, discípulo de Comas, estaba preparando la expedición de la balsa Acali, que tenía que cruzar el Atlántico. Como quedó patente, Comas estaba orgulloso de Santiago Genovés, a pesar de que no acababa de identificarse con aquel peligroso proyecto de cruzar el Atlántico.

Las únicas lecturas de edición española vinculadas a la Antropología durante la licenciatura, que yo recuerde ahora, fueron los libros de Sigmund Freud (Tótem y tabú, Alianza, 1967), Vere Gordon Childe (El nacimiento de las civilizaciones orientales, Península, 1968), Marcel Mauss (Sociología y antropología, Tecnos, 1971), Friedrich Engels (El origen de la familia, la propiedad privada y el Estado, Ayuso, 1972) y Bronisław Malinowski (Los argonautas del Pacífico occidental, Península, 1973).

Nuestra generación, formada en la universidad de Barcelona entre 1965 y 1975, no pudo obtener ninguna titulación en Antropología, ya que la licenciatura no se implantó hasta la segunda mitad de los años 1970. Bajo la tutela del Dr. Esteva, los miembros del grupo que se formó a su alrededor, cursamos licenciaturas cercanas a alguno de los campos de la antropología de las cuatro ramas, propias de la tradición boasiana, que era la herencia formativa de nuestro maestro. Aparte de cuatro licenciados en filosofía, hubo dos licenciados en lingüística, dos en prehistoria, dos en psicología y uno en historia del arte.

Esta tradición y esta trayectoria entraban en conflicto, tanto con la moda del estructuralismo como con el deslumbramiento hacia la antropología social británica que nos inoculó otro exiliado intelectual catalán, Josep R. Llobera, que, instalado en Londres desde inicios de los años 70, ejerció una notable influencia en todos nosotros, mediante sus visitas a Cataluña y las densas conversaciones que manteníamos con él y, sobre todo, mediante el extraordinario trabajo de traducción y edición de los clásicos de la antropología social, que dirigió en alianza con Jorge Herralde, propietario de la Editorial Anagrama ${ }^{8}$.

Volvamos al exilio republicano en México y a la manera cómo este influyó en nuestra formación académica y en nuestra filiación profesional. Juan Vicente Palerm, hijo del gran antropólogo y exiliado a México, Ángel Palerm, fue, a mediados de los años 1970, la segunda persona que nos conectó con la tradición mexicana de la antropología y, muy especialmente, con los enfoques marxistas y los planteamientos de la ecología cultural que se derivan de las corrientes del evolucionismo multilineal, que fueron las primeras fuentes de las que bebió Ángel Palerm unas décadas antes.

A lo largo del curso 1973-1974 Juan V. Palerm se desplazó varios fines de semana desde Madrid, donde ejercía como profesor ayudante en la Universidad Complutense, para discutir y debatir con un pequeño grupo de jóvenes licenciados los enfoques

${ }^{8}$ El primer título de la colección que dirigió Llobera, Biblioteca Anagrama de Antropología, fue una recopilación de textos de clásicos de antropología, seleccionado, editado y prologado por el mismo Llobera: La Antropología como ciencia, aparecido el año 1975 (Llobera 1975). Poco a poco muchos de nosotros fuimos colaborando en la colección de Llobera, aportando traducciones de los textos de los diferentes volúmenes de aquella extraordinaria colección. Otros textos que tuvieron mucho impacto en esta colección fueron: Antropología y feminismo (1979), La Antropología Médica en España (1980), Antropología de las sociedades mediterráneas (1981), Antropología Económica (1988), o la traducción de algunos de los textos de los autores clásicos de la antropología social británica: Radcliffe-Brown, Evans-Pritchard, Leach o Kahn. 
mexicanos y norteamericanos en el estudio del campesinado. Él, muy influenciado por su padre, se alineaba en las corrientes marxistas y en la tradición del evolucionismo multilineal. Lo importante para nosotros fue no solamente aquello que aprendimos de él, que fue muy sustancioso, sino las pistas y los contactos que nos proporcionó y que nos ayudaron a salir del círculo cerrado donde nos encontrábamos.

La dinámica que se generó a raíz de los encuentros con Juan V. Palerm impulsó la idea de aquello que en el año 1978 se convirtió en el Institut Català d'Antropologia, la primera asociación antropológica en el Estado español desde la instauración de la democracia. El ICA lo concebíamos como una plataforma, independiente de la Universidad, donde poder conectarnos con profesionales de la antropología social que nos abriera las puertas al conocimiento y que nos permitiera completar nuestra formación profesional. Durante el decenio que va de 1978 a 1987, en la sede del ICA en la calle Urgell pasaron antropólogos como Jonathan Friedman, Olivia Harris, Kenneth Brown y Ángel Palerm (1978), John Murra, Lawrence Krader y Josep R. Llobera (1979), Anne Cadoret, Teresa San Román y Pierre Bonte (1980), Anthony Leeds, Verena Stolcke, Lluís Mallart, Ubaldo Martínez Veiga y Josep R. Llobera (1982), Julian Pitt-Rivers, Louis Assier y Robert Jaulin (1983), Carmen Viqueira (1984), Gary McDonogh (1985), John Murra (1986), Marie E. Handmann y Raúl Iturra (1987)9.

Resulta significativa en esta lista de distinguidos colegas la incidencia de exiliados que la forman: Ángel Palerm (exilado republicano nacido en Ibiza y residente en México), John Murra (antropólogo norteamericano de origen rumano, combatiente en las Brigadas Internacionales en la Guerra Civil española), Carmen Viqueira (exiliada republicana de origen gallego y residente en México) o Raúl Iturra (chileno y exiliado de la dictadura pinochetista, residente en Portugal). También destacan aquellos colegas y compañeros españoles formados y/o residentes en el extranjero: Josep R. Llobera, Teresa San Román, Lluís Mallart o Ubaldo Martínez Veiga.

\section{EXILIO, MEMORIA, COMUNIDAD}

El fenómeno relevante, en todo este conjunto de situaciones y de procesos individuales y colectivos que estoy narrando, es la movilidad de ida y vuelta de las personas, de las ideas y del conocimiento que atesoran. Haciendo de la necesidad virtud, las experiencias del exilio aportan cosmopolitismo y, al mismo tiempo, ponen a prueba la capacidad de las personas de gestionar su vida en el marco contrastivo de unas alteridades que se confrontan con la propia identidad.

Como veremos más adelante, la experiencia de los exiliados republicanos que se instalaron en México nos permitirá reflexionar sobre el exilio como situación y como proceso, como un estatus legal y jurídico de refugio, y, al mismo tiempo, como una construcción social subjetiva, como un itinerario individual que se resuelve por vía del retorno al país de origen o por vía de la adopción de la nacionalidad del país de

\footnotetext{
9 Desde finales de los años 80, con el relevo generacional en la Universidad de Barcelona y la consolidación de los estudios de antropología en la Universidad Autónoma de Barcelona y en Tarragona (URV), cambiaron los objetivos y las prioridades del ICA y las universidades recuperaron íntegramente su misión formativa y divulgativa.
} 
residencia. Al mismo tiempo, la convivencia en México de los exiliados con los españoles y catalanes residentes en el país azteca con anterioridad al estallido de la Guerra Civil, pone sobre la mesa aquello que hay de experiencia común y compartida entre emigrantes y exiliados y aquello que los hace categóricamente casos diferenciados (Alonso y Baranda 1984; Lida 1997; Pla 1994 y 2000).

La literatura sobre el exilio republicano a México fue encabezada hasta mediados de los años 70 por historiadores, antropólogos y escritores mexicanos a pesar de la existencia de una abundante obra memorialista y testimonial escrita por los mismos protagonistas del exilio. Dentro de la historiografía mexicana destaca el análisis de las aportaciones que el exilio intelectual español hizo en el México postrevolucionario de mediados del siglo XX. Se trata, en general, de una literatura encomiástica que pone de relieve las grandes aportaciones de esta élite del exilio en los campos de las artes, la cultura, la enseñanza universitaria y en campos profesionales como la ingeniería, la medicina o las ciencias experimentales ${ }^{10}$.

Por su parte, la literatura memorialista de los exiliados republicanos nos ilustra sobre las circunstancias del final de la Guerra Civil, las condiciones de la salida de España y los primeros momentos de la llegada a México. También delimitan el proceso de adaptación a la sociedad mexicana y las oportunidades para insertarse en la vida activa, productiva y/o profesional. Otro aspecto que se destaca en esta literatura es el asociacionismo exiliado. La inmensa mayoría de estos testimonios van acompañados de expresiones de gratitud y reconocimiento hacia la acogida de que fueron objeto por parte de la sociedad mexicana y, en particular, por el general Lázaro Cárdenas ${ }^{11}$.

Si resumimos de manera esquemática aquello que nos aportan estos antecedentes, podemos afirmar que, mientras unos valoran las aportaciones del exilio republicano a México, otros evalúan las aportaciones del pueblo y la sociedad mexicana a los exiliados. Mi perspectiva, como creo que ya ha quedado claro, es la de analizar cuáles han sido las aportaciones de los exiliados y de las instituciones mexicanas que los acogieron o bien aquellas que ellos mismos crearon, en la creación de un marco de referencia para la antropología catalana de los 70 y, al mismo tiempo, en la creación de una conciencia generacional sobre el exilio republicano y sobre la memoria de este exilio.

Algunas de las grandes figuras en el análisis del exilio, por ejemplo Lida (2009) y Abellán (2001), coinciden en destacar la actitud sumamente proactiva del gobierno mexicano en el proceso de acogida de los exiliados republicanos. México fue una de las pocas voces, si no la única, que denunció las políticas de no intervención por parte de la Sociedad de Naciones. La complicidad entre el proyecto social, secularizador y

${ }^{10}$ Entre los trabajos más reconocidos y citados debemos mencionar a Bonfil (1993), El exilio español en México (1982), Enríquez (1990 y 2004), Fagen (1975), Giral (1994), León-Portilla (1978), Lida (1988, 1994 y 1997), Lida y Matesanz (2000), Martínez (1959), Matesanz (1978 y 2000), Pagni (2011), Palma (2006), Pla (1985, 2000 y 2007), Pla et al. (1993) y Pla, Ordóñez y Férriz (1997).

${ }^{11}$ En este apartado memorialista también hay espacio para la reflexión socio-histórica. Algunos de los textos más citados e influyentes en el estado de ánimo de los exiliados y en la manera de mirar y leer su realidad de "transterrados" se lo debemos a intelectuales exiliados como: Alonso (Meyer 1980), Aub (2008), Bladé (1976 y 1993), Buñuel (1982), Calders (1964), Gaos (1947 y 1966), Gili (1970), Martí (1989), Peyrí (1953), Somolines d'Ardois (1966) o Tísner [Avel·lí Artís] (Artís 1972, 1974 y 1989-1996). 
modernizador de la República española y el ideario de la Revolución mexicana, que se acababa de consolidar, era muy amplia. Los exiliados españoles, pese a ser muy diferentes entre ellos, representaban la legitimidad democrática del régimen republicano y eran vistos como una vanguardia social que, además, estaba formada por un porcentaje muy significativo de intelectuales y profesionales, que fueron muy bien recibidos y que, al mismo tiempo, hacían mucha falta en un país en pleno proceso de expansión post-revolucionaria y de modernización.

La hospitalidad de México con los republicanos españoles fue, pues, total, y no tuvo más límites que los que los propios españoles quisieron imponerle, la mayoría de los cuales no sólo se nacionalizaron mexicanos, sino que apoyaron el proceso político de la Revolución; es decir, que se adhirieron entusiastamente a la política progresista del Estado mexicano (Abellán 2001: 93).

Este buen recibimiento era generador de las mejores expectativas. No obstante, como señala Clara Lida (2009: 87 y ss.), las cosas no fueron tan fáciles para los exiliados españoles, ya que México era para la mayoría de ellos terra incognita. ¿Cómo debían percibir, en el momento de su llegada, esta nueva realidad desconocida? ¿Cómo pasaron de los estereotipos a una aproximación más reflexiva y vivencial de la realidad de un país, aún eminentemente rural y que hacía menos de 20 años que había salido de una guerra civil muy sangrienta? Por otro lado, la misma autora se pregunta cuál era la percepción que los mexicanos, en general, tuvieron de los exiliados. Nos recuerda que en aquellos tiempos habían dos categorías para distinguir a los diferentes tipos de españoles: rojos y gachupines. Y añade:

En el imaginario mexicano, los españoles eran vistos a través de la lente nacionalista de la Revolución como los antiguos colonizadores y las élites económicas del XIX que durante siglos habían abusado de su poder social y material, afectando al grueso de los mexicanos menos favorecidos (Lida 2009: 88).

En todo caso, está claro que en muy poco tiempo los refugiados españoles supieron tomar distancia del estereotipo del gachupín, marcando un perfil propio donde se mostraba la complicidad de estos rojos con la Revolución mexicana y su proyecto nacional que, en muy buena medida, contribuyeron a consolidar con su destacado trabajo intelectual y material. Según datos de Pla (2000), el 58\% de los refugiados estaba constituido por profesionales, catedráticos y docentes, intelectuales, científicos y artistas, mientras que el $41 \%$ adscrito en el sector secundario provenía de los sectores más modernos de la industria. Desde bien temprano, la literatura sobre el exilio canonizó una lectura en positivo sobre este proceso, que ponía el énfasis especialmente en la tarea intelectual y en las numerosas iniciativas en el mundo editorial (Bernecker 2011: 41 y ss. $)^{12}$.

Especialmente durante los primeros momentos de la llegada a México las dos colonias españolas en México tuvieron muy poca conexión. La mayoría de antiguos residentes de origen español, muchos de ellos empresarios de éxito, tenían un perfil

\footnotetext{
${ }^{12}$ No cabe ninguna duda de que en el proceso de selección de los exilados españoles que podían viajar e instalarse en México, el gobierno mexicano primó la presencia de profesionales, académicos y, en general, de personas con altas cualificaciones (Lida 1994, 1997 y 2009; Pla 1994, 2000 y 2007).
} 
conservador y, a lo largo de la Guerra Civil, fueron mucho más cercanos al alzamiento fascista. Para los exiliados republicanos el concepto de comunidad y/o de identidad nacional no tenía ningún sentido, refiriéndose a estos sectores conservadores que no solo se alineaban con la contrarrevolución de Franco, sino que décadas antes habían dado apoyo a la Dictadura mexicana de Porfirio Díaz. Si partimos de la teoría, plenamente justificada en este contexto, de las dos Españas, la España republicana y exiliada se sentía más próxima a los ideales mexicanos que a los ideales de sus coterráneos gachupines.

Esta complicidad, este buen recibimiento, llevó a que la visión de los exiliados, al menos la de aquellos sectores que pudieron escribir y difundir su pensamiento, fuera la de una experiencia de continuidad con su ideario progresista y con sus trayectorias profesionales, cosa que en su propia tierra hubiera sido imposible. Se establece una continuidad entre la tierra europea y la tierra americana, atravesada por el puente de unos mismos ideales compartidos. Más que vivir la situación como un verdadero destierro, muchos de ellos conceptualizaron la situación en términos menos rotundos. Pese a reconocer la frustración de estar lejos de su país, paisaje y paisanaje, la experiencia mexicana hacía perdurar los ideales y las ilusiones depositadas en participar en la construcción de una sociedad más justa, laica y progresista. Esta corriente de opinión queda reflejada en diferentes escritos de uno de los más grandes y reconocidos exiliados republicanos, José Gaos:

(...) es claro que entre los refugiados españoles adaptados a México no existe una impresión de destierro, sino más bien de traslado dentro de la propia tierra española, es decir, de "transtierro", y así lo confirma Gaos cuando dice: "En México no me sentía desterrado, sino "transterrado", con palabra que ha hecho fortuna, sin duda por dar expresión a una realidad psicológica, colectiva" (Abellán 2001: 95).

Clara Lida (2011) utiliza la imagen del estar en vilo como una manera de expresar la situación de desgarro emocional, de provisionalidad, de espera, que supone la situación del refugiado que, pese a recibir una excelente acogida, está pendiente de aquello que sucede en su país, en su tierra, en su continente. Tras la instauración del régimen fascista en España, el nazismo en Europa hizo ver a muchos que la situación de provisionalidad podría durar mucho tiempo. Para la mayoría de ellos, América podría convertirse de nuevo en la tierra prometida donde poder materializar los anhelos de revolución social que todos los republicanos exiliados codiciaba. Entre los escritores catalanes, como Bartra, Calders o Tisner, entre ellos, la fidelidad a la lengua y la perspectiva del retorno al país se mantuvo incorruptible, para otros, el enraizamiento en la república mexicana fue su gran alternativa. En el caso de los antropólogos catalanes, que pasamos a presentar a continuación, prevaleció esta segunda actitud, entre otras razones porque la antropología tenía muchas mejores condiciones de desarrollo en México que en la España franquista, donde las ciencias sociales eran silenciadas o reprimidas.

\section{LOS ANTROPÓLOGOS CATALANES DEL EXILIO MEXICANO}

Se trata de dieciocho personas, dos de las cuales llegaron a México en el cenit de su carrera profesional: Pere Bosch i Gimpera (arqueólogo y Rector de la Universidad 
de Barcelona) y Joan Comas Camps (pedagogo y antropólogo físico, originario de Menorca $)^{13}$. Otros cuatro llegaron muy jóvenes a México y se formaron como antropólogos en la ENAH y en la UNAM: Ángel Palerm Vich, Claudi Esteva Fabregat, Pedro Armillas García y Santiago Genovés Tarazaga ${ }^{14}$. Finalmente, tenemos una segunda generación compuesta por ocho colegas: Gloria Artís Espriu y Glòria Artís Mercadet (hijas, respectivamente de los hermanos Arcadi i Avel·lí Artís), Armando Bartra Vergés y Roger Bartra Murià (nacidos en México e hijos, respectivamente de los hermanos Carles y Agustí Bartra), Andrés Fábregas (hijo de exiliado catalán), Jordi Gussinyer Alfonso (hijo de exilados catalanes) y Jacinta y Juan Vicente Palerm (hijos de Ángel Palerm y de Carmen Viqueira).

Junto con los catorce antropólogos de origen catalán, tenemos que registrar la presencia en México de otros cuatro antropólogos, formados en México y originarios de otros lugares de España: Pedro Carrasco Pizana, José Luis Lorenzo Bautista, Enrique Nalda Hernández y Carmen Viqueira Landa. Este será nuestro universo de análisis. Empezaremos por hacer una presentación sucinta de nuestros protagonistas ${ }^{15}$.

\section{Pere Bosch i Gimpera}

Filólogo clásico y prehistoriador de formación, fue catedrático de Historia Antigua, decano de la Facultad de Filosofía y Letras y Rector de la Universidad de Barcelona (1933-1939). Entre 1937 y 1939 fue Conseller de Justicia de la Generalitat de Catalunya. En el año 1915 fue nombrado director del Servei d'Excavacions de l'Institut d'Estudis Catalans. En 1916 accedió a la cátedra de Historia Antigua de la Universidad de Barcelona. En 1919 publicó Prebistòria catalana (Bosch i Gimpera 1919). Dentro de su extensa producción escrita anterior a la Guerra Civil, en el año 1932, publicó un extenso volumen dedicado a la etnología, Etnología de la Península Ibérica, que tuvo un gran impacto y recibió elogiosos comentarios de su colega vasco José María de Barandiarán (Bosch i Gimpera 1932). Fue uno de los creadores de la Asociació Catalana d'Antropologia, Etnografia i Prehistòria y en el año 1929 organizó el Congreso In-

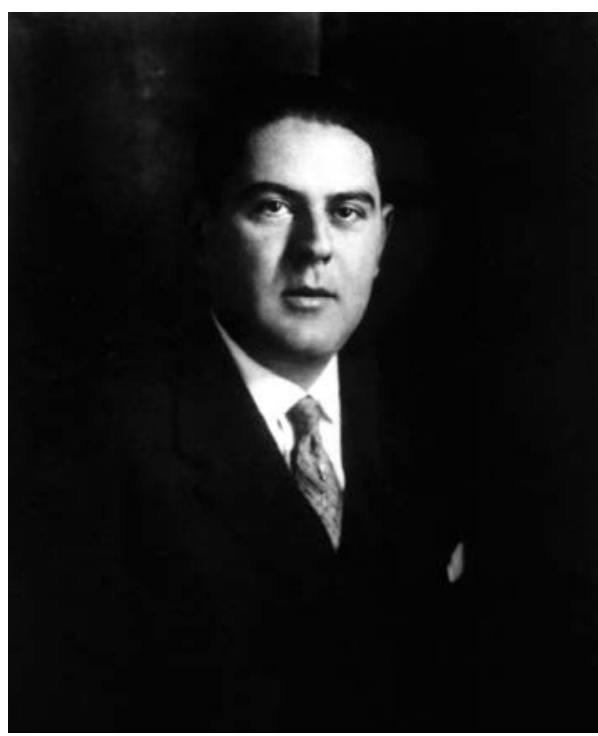

Pere Bosch I Gimpera. Fuente: Museu d'Arqueologia de Catalunya. Disponible en: <http:/ /bit.ly/2g6EbO1>. Fecha de acceso: 3 oct. 2017. ternacional de Arqueología.

\footnotetext{
${ }^{13}$ Los profesores Bosch i Gimpera y Comas han de ser considerados maestros de maestros.

${ }_{14}$ Esta es la generación de nuestros maestros.

15 Tomaremos también en cuenta a una tercera generación y a la presencia catalana en México de personas no exiladas.
} 
En su exilio mexicano fue profesor tanto en la Escuela Nacional de Antropología e Historia (ENAH) como en la Universidad Nacional Autónoma de México (UNAM). En 1944 publicó en México su libro La formación de los pueblos de España (Bosch i Gimpera 1944), seguido dos años después por una Història de Catalunya (Bosch i Gimpera 1946). Entre los años 1948 y 1952 ejerció como jefe de la División de Filosofía y Humanidades de la UNESCO. En 1971, tres años antes de su muerte, obtuvo la nacionalidad mexicana. A lo largo de su prolongado exilio mantuvo una estrecha relación con su colega y antiguo discípulo Lluís Pericot García. Junto con su dilatada producción científica, centrada en el análisis de los pueblos europeos del Eneolítico hasta la Edad de Bronce, también abordó una extensa tarea de divulgación, destacando trabajos como El Estado actual de la investigación de la cultura ibérica (Bosch i Gimpera 1929), L'art grec a Catalunya (Bosch i Gimpera 1938), Las razas humanas (Bosch i Gimpera 1928), El hombre primitivo y su cultura (Bosch i Gimpera 1945), o El problema de las Españas (Bosch i Gimpera 1981). Es necesario destacar también su libro de memorias, editado póstumamente, Memòries (Bosch i Gimpera 1980).

\section{JOAN COMAS I CAMPS}

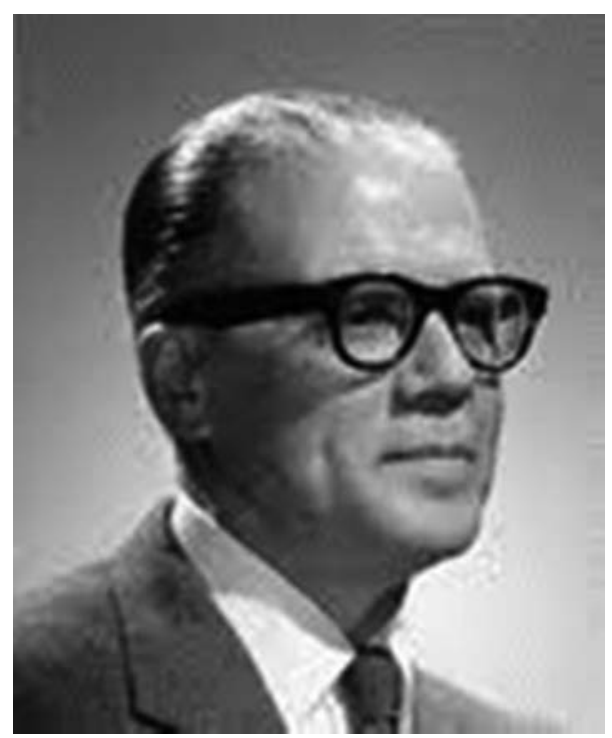
cana de Antropología Biológica. Disponible en: <http://amabmex.tripod.com/miembros/ juancomas.html>. Fecha de acceso: 3 oct. 2017.
Joan Comas i Camps. Fuente: Asociación Mexi-

Antropólogo físico nacido en Alaior (Menorca) en el año 1900. Estudió Magisterio y Biología en la Universidad Central de Madrid, donde se especializó en el campo de la antropología física. En su etapa madrileña se vinculó al movimiento estudiantil, habiendo sido compañero de Federico García Lorca o Luis Buñuel. Acabados sus estudios en Madrid, se marchó a Suiza para continuar su formación, habiendo sido alumno de Jean Piaget en el campo de la pedagogía y, sobre todo, de Eugène Pittard, uno de los fundadores de la antropología física moderna.

Refugiado en México como resultado de la Guerra Civil en el año 1939, llevó a cabo una intensa tarea investigadora alrededor de la realidad de los pueblos indígenas de Mesoamérica. Vinculado a la defensa de la causa indígena, fue uno de los pioneros de los derechos humanos en México. Desarrolló también una meritoria tarea docente en la ENAH y en la UNAM, muy especialmente en el Instituto de Investigaciones Antropológicas (IIA) del que fue uno de los fundadores y director. Murió en Ciudad de México el año 1979.

Junto a decenas de artículos en revistas científicas, su tarea docente, divulgadora y militante gira alrededor de unos setenta libros. A caballo entre la docencia y la inves- 
tigación publicó Paleoantropología y evolución (Comas 1959), La antropología física en México (Comas 1960), Manual de antropología física (Comas 1966), Unidad y variedad de la especie bumana (Comas 1967) e Introducción a la prebistoria general (Comas 1971). En el campo de la divulgación dirigió Las razas humanas (Comas 1946). Su contribución mayor a la crítica al racismo y a la defensa de los derechos humanos aparece en Razas y racismo (Comas 1972) ${ }^{16}$.

\section{Pedro Armillas García}

Donostiarra, hijo de familia de comerciantes que se instala en Barcelona en la década de los años 1920. Estudió bachillerato en el Instituto Jaime Balmes y realizó estudios universitarios incompletos de Arquitectura, Bellas Artes y Filosofía y Letras entre 1932 y 1936. En la Guerra Civil ejerce como topógrafo en unidades de artillería. Estos conocimientos elementales de topografía le permitirían, después de su llegada a México, obtener un trabajo cualificado en la Comisión Agraria de Chiapas, lo que le permitió entrar en contacto con los pueblos indígenas, marcando su inclinación hacia su futuro profesional dentro de la antropología.

Desde 1940, ya matriculado en la carrera de Antropología en la ENAH, empieza a participar en excavaciones arqueológicas trascendentales, bajo la dirección de Alfonso Caso (Xochicalco, Teotihuacan, Monte Albán), aprovechando de nuevo sus conocimientos topográficos. Ya en el año 1945

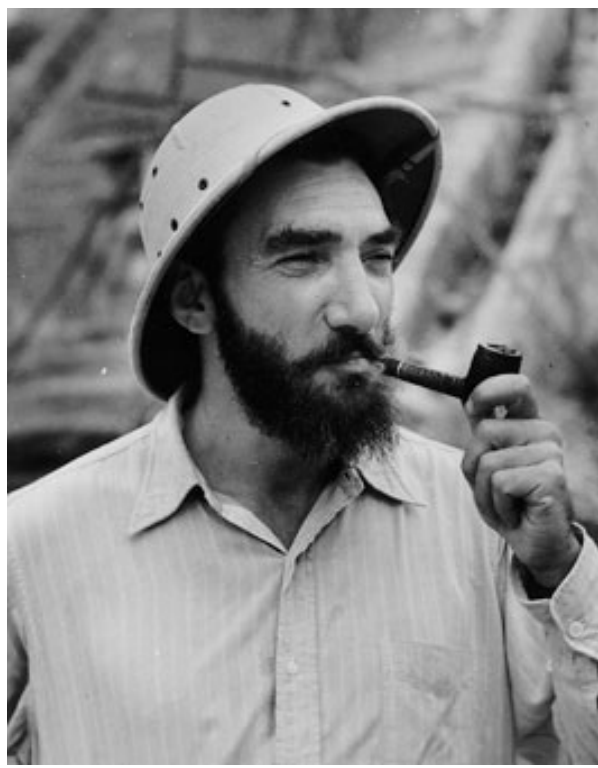

Pedro Armillas. Fuente: Mediateca del INAH. Disponible en: <http://mediateca.inah.gob.mx/ repositorio/islandora/object/fotografia\% 3A447062>. Fecha de acceso: 3 oct. 2017. sucede a su maestro, nombrado rector, en la Cátedra de Arqueología Mexicana, desarrollando una intensa tarea docente e investigadora. Al año siguiente obtiene una beca Guggenheim, que le permite viajar a los Estados Unidos y completar su formación como antropólogo. Allí, bajo la influencia capital de Paul Kirchhoff, queda atrapado por el enfoque del evolucionismo de Gordon Childe y de la ecología cultural. Los nuevos planteamientos de Armillas entran en conflicto con los intereses de sus mentores mexicanos, viéndose obligado a iniciar aquello que él mismo consideró su segundo destierro, ejerciendo como profesor en diferentes universidades norteamericanas, entre ellas, Michigan, Southern Illinois y Chicago. Mantuvo siempre contacto y amistad con Pere Bosh Gimpera y Joan Comas. Su obra, no demasiado abun-

${ }^{16}$ En 1979 la Revista Española de Antropología Americana publicó una bibliografía exhaustiva del Prof. Comas. 
dante pero muy influyente, se orienta al análisis evolutivo de los sistemas políticos y a su impacto sobre el control del territorio (Armillas 1948, 1951 y 1975), los sistemas hidráulicos y la evolución de la agricultura (Armillas 1949 y 1966).

\section{Santiago Genovés Tarazaga}

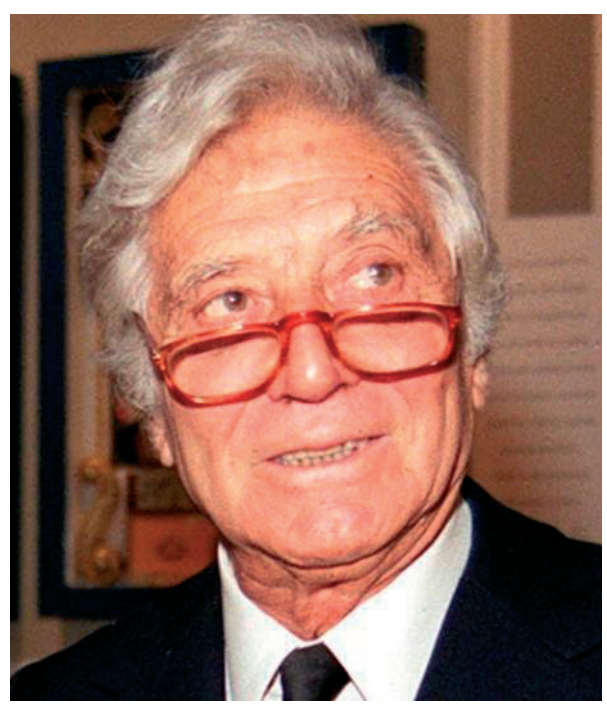

Santiago Genovés Tarazaga. Fuente: diario El Universal, México. Disponible en: <http:// archivo.eluniversal.com.mx/cultura/2013/ santiago-genoves-muerte-948563.html> Fecha de acceso: 3 oct. 2017.

Nació en Ourense en el año 1923, aunque, posteriormente, su familia se trasladó a Valencia, ciudad donde vivió durante la Guerra Civil. Llegó a México con 15 años de edad, sin haber acabado bachillerato. Estudió en la ENAH y, posteriormente, realizó su doctorado en Antropología Física en la Universidad de Cambridge.

Científico destacado y de proyección internacional, su campo principal de estudio durante los años 50 y 60 fue la paleoantropología, siguiendo la trayectoria iniciada con su tesis doctoral (Genovés 1956) y con trabajos publicados con el que fuera su director de tesis, el Prof. D. R. Bainbridge (Genovés y Bainbridge 1956). Dentro de esta misma línea de identificación de restos óseos trabaja en diferentes yacimientos antropológicos como Coixtlahuaca (Estado de Oaxaca), o Tepexpan (Estado de México) (Genovés 1958 y 1960), revisa y afina técnicas de datación y de establecimiento de índices que permiten la identificación del sexo, la edad y la altura de los fósiles (Genovés 1965 y 1967). A lo largo de su trayectoria, como investigador del IIA-UNAM, mantuvo una relación estrecha con su primer maestro, el Prof. Comas, con quien realiza diferentes publicaciones sobre el estado de la Antropología Física en México (Genovés y Comas 1964).

Otro ámbito de investigación en el que el Prof. Genovés mostró su implicación cívica y su ideología progresista, compartida por la inmensa mayoría de los antropólogos y antropólogas mexicanos (en especial con su maestro, el Prof. Joan Comas) fue el racismo (Genovés 1966). Pero, quizás, una parte importante de su reputación internacional está relacionada con sus estudios sobre la violencia, que muestran su militancia contra el paradigma de la sociobiología y otras teorías post-evolucionistas, que defendían el carácter innato de la agresividad y la violencia humana. Promovió la Declaración sobre la violencia (Sevilla, 1986), que señala que "1. La violencia no está genéticamente determinada; 2. La violencia no está inscrita en nuestro cerebro; 3. La violencia no proviene de nuestro pasado animal; 4. En el proceso de evolución no ha habido una selección mayor hacia el comportamiento agresivo o violento que hacia otro tipo de comportamientos; y 5 . La violencia no es hereditaria". Esta declara- 
ción fue subscrita por la UNESCO y por más de 100 sociedades científicas, correspondientes a un amplio abanico disciplinario: neurología, fisiología, bioquímica, psiquiatría, psicología, sociología y antropología (Genovés 1986).

Dentro de esta línea de investigación sobre violencia y agresividad humana, uno de los experimentos más notorios fue la organización de la expedición trasatlántica en la balsa Acali ('Casa en el Agua'), donde Genovés consiguió reunir a 10 personas (6 mujeres y 4 hombres), que provenían de la medicina, sexología, psiquiatría, psicología, sociología y antropología. Su finalidad era analizar el comportamiento de los viajeros en un contexto cerrado y de convivencia inevitable: "la historia fue larga en ese laboratorio aislado e inescapable». A lo largo de 101 días amontonados en un pequeño espacio en medio del Océano, Genovés pudo comprobar, "de manera fehaciente y brutalmente directa, que la violencia se relaciona con la búsqueda de liderazgo y poder. Esta es la fuente número uno de la violencia”. Al mismo tiempo consideraba que, tal vez, la segunda fuente de violencia es el cambio de roles: "en nuestros papeles de jefes, amigos, hijos y padres, por ejemplo". Así, hace notar que "nos pasamos el día cambiando de roles y que cuando ese cambio es muy súbito, se origina un conflicto". Fruto de esta experiencia el autor publicó la monografía del viaje (Genovés 1975), así como otros libros de reflexión derivados (Genovés 1974 y 1976).

\section{Claudi Esteva Fabregat ${ }^{17}$}

Nacido circunstancialmente en Marsella en noviembre de 1918, hijo de una familia barcelonesa, residente en el barrio de Sants. Llegó a México el 13 de junio de 1939 a bordo del barco Sinaia, en la primera gran expedición de exiliados españoles que salieron de Francia. Muchos de los 1.800 refugiados de esta expedición provenían del campo de internamiento de Sant Cebrià [Saint Cyprien sur Mer], Departamento de los Pirineos Orientales. Esteva, como tantas otras fuentes, narra las penalidades, humi-

Claudi Esteva Fabregat. Fuente: Mediateca Universitat de Barcelona. Disponible en: <http:/ /www.ub.edu/ubtv_proves/es/video/15-minutsamb-claudi-esteva $>$ Fecha de acceso: 3 oct. 2017.

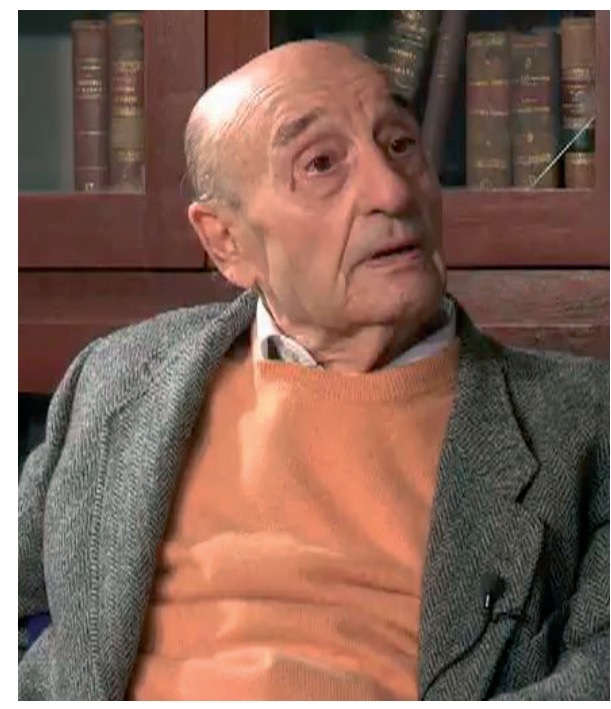

${ }^{17}$ Hallándose este texto en la última fase de corrección se ha producido el fallecimiento del Dr. Claudi Esteva Fabregat. El deceso tuvo lugar en Barcelona el pasado día 4 de setiembre. El Prof. Esteva hubiera cumplido en noviembre los 99 años. Toda la antropología española está de luto, como quedó patente en el XIV Congreso de la FAAEE, celebrado en Valencia los pasados días 5 a 9 de setiembre. En estas fechas, además, celebrábamos el cuadragésimo aniversario del Primer Congreso Español de Antropología, celebrado en Barcelona en la primavera de 1977, bajo su impulso y presidencia. Se acaba de cerrar una larga etapa de magisterio en España y en México. 
llaciones, hambre y frío que pasaron durante este internamiento. También narra la emoción que provocó en todos los exiliados el cálido recibimiento de que fueron objeto a su llegada a Veracruz. Todos los refugiados, después de las penalidades de la guerra, experimentaban una sensación de libertad, de alivio, manteniendo a la vez sus contactos, que les permitirían, entre otras cosas, conocer la evolución de la situación en España y en Europa, inconscientes, en la mayoría de los casos, de que estaban acabando de iniciar una larga etapa que, para muchos, les mantendría en México para el resto de sus vidas:

Teníamos todos la idea en la cabeza de que al cabo de tres meses volveríamos a casa. Es decir, no teníamos una conciencia muy clara de que aquello duraría mucho tiempo. Pensábamos que vendría la guerra [europea], que probablemente la ganaríamos nosotros, los demócratas, y que volvería la República a España. Esta era la convicción, pero estábamos totalmente equivocados, evidentemente (Brufau, Permanyer y Zulet 2011: 3-4).

Hasta el año 1947, en que se inscribió en la ENAH para estudiar Antropología, se ganó la vida haciendo de jugador y entrenador de fútbol, razón por la cual vivió cinco años en Puebla (1940-1945), antes de volver a México DF. La vida social de los exiliados era muy intensa, tanto a nivel de organizaciones políticas (Esteva era miembro del Partido Socialista Catalán), como a un nivel más informal, a medio camino entre la sociabilidad y la búsqueda de contactos para ganarse la vida:

En mi caso, junto con otros catalanes, fui al Orfeó Catalá, donde nos recibieron muy bien los antiguos residentes, y allí fue donde empezó a formarse "la red": un viejo residente le daba empleo a un recién llegado, éste hacía correr la voz entre sus amigos y se ponía en marcha la bolsa de trabajo. Digamos que esta bolsa estaba basada en relaciones de grupo "étnico": los catalanes por una parte, los vascos por otra, los gallegos por otra... (Santos 2009).

Cuando Esteva se matriculó en la ENAH su idea inicial fue la de seguir los estudios de Antropología Física, motivado en buena medida por la maestría de Joan Comas y Pere Bosch Gimpera, profesores de la ENAH. En esta institución universitaria se organizó también una red de estudiantes procedentes del exilio, la mayoría de ellos catalanes:

Allí conocí a compañeros míos que entraron por los mismos motivos que yo. Resultó que el grupo catalán dentro de la ENAH era el grupo de extranjeros más numeroso: estaba Molins y Fàbrega, que era el director de La Batalla; estaba Àngel Palerm, que venía del anarquismo, de la CNT; estaba Pedro Armillas, que acabó siendo un gran arqueólogo, uno de los mejores arqueólogos que ha dado México... En fin, había muchos. Formamos un grupo de unos diez (Brufau, Permanyer y Zulet 2011: 6).

El ambiente intelectual de aquellos años en la ENAH era extraordinario. Junto al profesorado autóctono, un amplio abanico de grandes profesionales de la antropología visitaban México y ofrecían cursos en aquella institución: los norteamericanos George Foster, Isabel Kelly o Robert Redfield, el francés Jacques Soustelle. De todas formas el antropólogo de origen extranjero más influyente en aquellos años fue Paul Kirchhoff, fundador de la ENAH e investigador de la UNAM, hasta su muerte (1972). Impulsó una línea de pensamiento de filiación marxista y fue quien estableció el concepto de Mesoamérica como un área cultural diversa, pero que compartía muchos 
elementos civilizatorios. Fue decisivo su impulso de una visión etnográfica y etnohistórica orientada al análisis de las culturas y sociedades primigenias:

(...) el énfasis en la etnografía y la historiografía [en aquella época], además de los requerimientos del Estado, fue la que veía el objeto de estudio de la antropología en las sociedades indias. Lo que es falso es afirmar que no existían otras propuestas en la escuela de aquellos días. Tan es así que la tesis de Claudio Esteva Fabregat (figura importante de la antropología contemporánea en España) versó sobre los problemas de la clase obrera. Así mismo, la llamada generación crítica que se forjó en la Escuela Nacional a mediados de los años cincuenta y principios de los sesenta, tocó también temas diferentes a los de la cuestión indígena (Fábregas 1992: 13).

Claudi Esteva, en una entrevista reciente, expresa su discrepancia respecto del mainstream de la academia mexicana de aquellos años en estos términos:

(...) en aquel momento llegué a la conclusión de que llegar a ser antropólogo indigenista no entraba dentro de lo que pensábamos que tenía que ser la antropología, teniendo en cuenta que no se contemplaban las culturas urbanas y las civilizaciones modernas. Yo en aquel momento estaba convencido de que la antropología no empezaba allí donde terminaba el asfalto. Es decir, la antropología debía incluir también a las sociedades modernas (Brufau, Permanyer y Zulet 2011: 9).

La lectura de autores como Ruth Benedict, Clyde Kluckhohn o Abraham Kardiner, junto con la influencia del psicoanalista mexicano Raúl González (Brufau, Permanyer y Zulet 2011: 11), que le presentó al psicoanalista alemán Erich Fromm, dieron una orientación decisiva al enfoque teórico y a la trayectoria profesional de Claudi Esteva a lo largo de toda su trayectoria vital y profesional:

Estuve cinco años siendo psicoanalizado por Fromm y estuve trabajando en el análisis de materiales clínicos, dándoles una comprensión de tipo cultural (Brufau, Permanyer y Zulet 2011: 13).

Este acercamiento de Esteva al psicoanálisis tuvo consecuencias directas en el inicio de su carrera académica:

Raúl González Enríquez, que era muy amigo de Alfonso Caso, un antropólogo-arqueólogo, me pidió que diera un curso sobre Cultura y Personalidad en la ENAH, de manera que esta fue mi orientación. Di este curso, que se completó con una Historia de la Cultura y con uno de Análisis de la Personalidad. Y desde el año 1953 hasta 1956 estuve dando estos cursos en la ENAH (Brufau, Permanyer y Zulet 2011: 13).

A su vuelta a España se instaló en Madrid. Llevaba cartas de recomendación que le había hecho el Dr. Pere Bosch i Gimpera, lo que le allanó el terreno para que pudiera conseguir de manera relativamente rápida los títulos universitarios que le habilitaran para poder ejercer como antropólogo en España, pese a no existir la posibilidad de que le fueran reconocidos los estudios realizados en México. Así el año 1957 obtenía el título de licenciado en Historia de América por la Universidad Complutense de Madrid. El año siguiente se doctoró en Filosofía y Letras en la misma universidad (Sección de Historia de América), con su tesis: El carácter nacional azteca. Fue profesor encargado de curso en la UCM entre los años 1958 y 1968. En 1965 fue nombrado director del Museo Nacional de Etnología de Madrid, cargo que ocupó hasta 
1968. El año 1966 fundó la Escuela de Estudios Antropológicos de la que fue director hasta su vuelta a Barcelona, en 1968.

Este mismo año ganó por oposición la plaza de profesor agregado de Etnología en la Universidad de Barcelona y en 1971 obtuvo la primera cátedra de Antropología Cultural en el Estado español. En 1972 fundó el Departamento de Antropología Cultural de la Universidad de Barcelona, del que fue director hasta su jubilación en el año 1986. Paralelamente, fue director del Centro de Etnología Peninsular e Hispanoamericana, del CSIC de Barcelona (años 1968-1986). En el marco del CSIC fundó y dirigió la revista Éthnica. Revista de Antropología (1971-1986).

\section{6. ÁNGEL PALERM Vich}

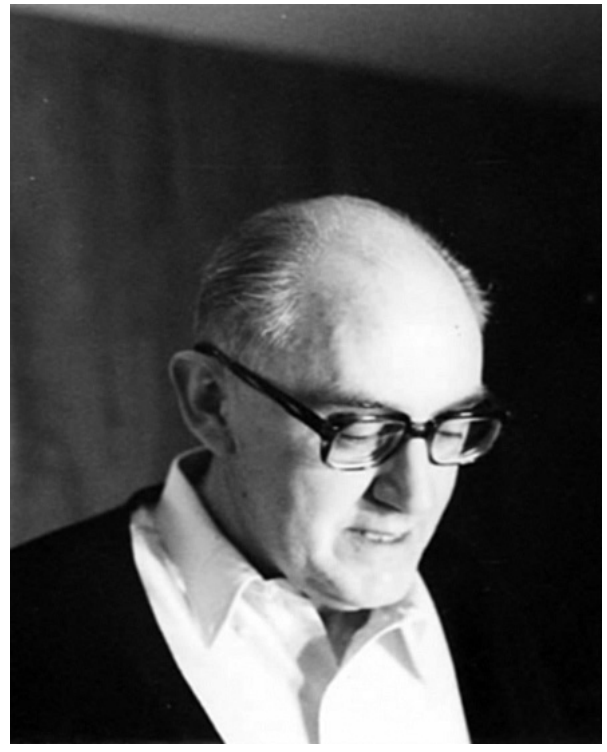

Ángel Palerm. Fuente: ArKeopatías. Disponible en: <https://arkeopatias.wordpress.com/ 2013/02/11/catedra-angel-palerm/>. Fecha de acceso: 3 nov. 2017.

Nació en Ibiza el 11 de septiembre de 1917, hijo de una familia de comerciantes. Fue activista y militante anarquista desde muy joven: fue miembro de la sección local de la FUE, activista de la FAI en la isla y colaborador de la revista anarcosindicalista balear Cultura Obrera. Cuando estalló la Guerra Civil se encuadró en la columna menorquina de la CNT y, posteriormente, después de los hechos de mayo de 1937, dejó el anarquismo para afiliarse al PSUC y al ejército regular republicano, donde llegó a ser comandante del ejército de tierra y jefe de Estado Mayor de la Brigada Internacional Garibaldi.

Acabada la guerra, y tras un tiempo confinado en un campo de concentración francés, pudo salir por Burdeos en julio de 1939 a bordo del barco Mexique en dirección al puerto de Veracruz, en la costa atlántica mexicana. En el año 1941 conoció y se casó con Carmen Viqueira Landa, exiliada republicana, nacida en Badajoz de familia gallega originaria de Betanzos. Palerm mantuvo su activismo en las Juventudes Socialistas Unificadas (JSU), habiendo dirigido revistas como Juventud de España, La lucha de la Juventud y Presencia. El año 1945 abandonó el PCE por discrepancias en su línea política y militó un par de años en un grupo llamado Movimiento de Oposición Comunista.

Animado por su mujer, Carmen, reemprendió los estudios el año 1945, en 1949 se licenció en Historia por la UNAM y en 1952 obtuvo el grado de maestro en Etnología en la $\mathrm{ENAH}^{18}$. Ante la falta de perspectivas laborales a corto plazo, y siguiendo el

${ }^{18}$ En la ENAH tuvo como profesores a grandes maestros como Isabel Kelly, Sol Tax, Pedro Armillas, Pedro Carrasco, Ricardo Pozas, Robert Redfield, George Foster o Paul Kirchhoff. La pro- 
consejo del Prof. Joan Comas, aceptó una plaza de funcionario en la Unión Panamericana, lo que implicó su traslado a los EUA.

Como destaca el Prof. Jorge Alonso (2008) en su esbozo biográfico, publicado en la web del Colegio de Etnólogos y Antropólogos Sociales: "Ángel hablaba de cuatro exilios: de Ibiza a España, de España a Francia, de Europa a México, y de México a Estados Unidos". Allí vivió 13 años, primero como editor de la Revista Interamericana de Ciencias Sociales, después (1961-1965) como director del Departamento de Asuntos Sociales de la Organización de Estados Americanos. Desacuerdos entre su talante progresista y antiimperialista, la hegemonía creciente de los EUA en la organización, la muerte de Kennedy y las críticas de Palerm a la guerra de Vietnam, significaron el fin de esta etapa ${ }^{19}$.

En 1965 volvió a México. Entre 1965 y 1966 fue representante especial del secretario general de la OEA en varios países de América Latina. Ejerció de profesor en la Universidad Mayor de San Marcos de Lima, en Perú. Fue profesor de etnología en la ENAH hasta que en 1968 abandonó el cargo como protesta por la represión de los estudiantes del 2 de octubre de 1969 y por la expulsión de los profesores comprometidos con el movimiento estudiantil. Trabajó durante doce años como profesor del Departamento de Antropología en la Universidad Iberoamericana, donde permaneció gran parte de su vida académica. Allí fundó y dirigió la carrera de Antropología Social y el Instituto de Ciencias Sociales de esta universidad. A partir de 1973, fue también director del Centro de Investigaciones Superiores del INAH (CIS-INAH) que, posteriormente, pasó a denominarse CIESAS y a independizarse del INAH.

Desde el punto de vista de la investigación realizó trabajos de campo en Guatemala, Perú, Israel y, sobre todo, en México. Sus tesis antropológicas lo llevaron a criticar la ortodoxia marxista para adoptar posiciones abiertas a un evolucionismo multilineal que comportaba prever la posibilidad de la supervivencia del capitalismo o de su transición hacia otros sistemas que no tenían que ser necesariamente el socialismo. Su aplicación del modelo del despotismo oriental para explicar el estalinismo provocó respuestas airadas de los sectores ortodoxos. Se esforzó por encontrar un método comparativo que fuera de aplicación a las diferentes formaciones sociales y se centró, en especial, en la agricultura mesoamericana (Palerm y Wolf 1972), los sistemas prehidráulicos (Palerm 1973), en el concepto de modo de producción (Palerm 1976), en el análisis de la relación entre marxismo y antropología (Palerm 1980) y en la formación del sistema colonial.

Pero se debe destacar una contribución muy singular, que es la muestra de su carácter de maestro indiscutible de la Antropología. Nos referimos a su Historia de la

\footnotetext{
fesora Kelly fue su introductora al trabajo de campo en un proyecto sobre el área de El Tajín (Veracruz). Las aportaciones de Palerm a aquel estudio llegaron a ser tan relevantes que Kelly le hace coautor del primer volumen del libro The Tajin Totonac. Subsistence, Shelter and Technology (Kelly 1952). Pedro Armillas y Pedro Carrasco, exilados republicanos como él, también se habían formado en la ENAH y hacía poco tiempo que habían acabado sus estudios cuando fueron profesores de Palerm. Otros exilados, como Santiago Genovés y José Luis Lorenzo, fueron compañeros de Palerm en la ENAH. Poco a poco se fueron consolidando los lazos de amistad entre los miembros de esta pequeña comunidad de exilados antropólogos.

${ }^{19}$ Durante su estancia en Estados Unidos, en el año 1962, obtuvo su grado de doctor en Ciencias Sociales en el Instituto de Planeación Regional del Perú.
} 
etnología, concebida en seis volúmenes y de los que dejó publicados a su muerte los tres primeros, dedicados respectivamente a Los precursores (vol. 1), Los evolucionistas (vol. 2), Tylor y los profesionales británicos (vol. 3) (Palerm 2005 [1976], 2010a [1974] y 2010b [1977] $)^{20}$. Este ingente proyecto se fundamenta en tres pilares básicos, que muestran la visión de Palerm sobre la antropología:

1. La antropología, a diferencia de otras ciencias, no posee un cuerpo teórico cerrado, sino que consiste en un conjunto de teorías vinculadas a problemas y enfoques particulares, lo que implica la necesidad de situar históricamente las formulaciones teóricas en su contexto histórico particular. Por lo tanto, dedicarse a la historia de la antropología quería decir trabajar sobre la teoría antropológica (Alonso 1979).

2. La etnografía se convierte en una tradición cultural y casi en un género literario, junto con los relatos de viaje, ya desde la tradición clásica inaugurada por autores como Heródoto, César, Estrabón o Tácito, hasta nuestros días. Esta tradición cultural de contenido humanista modifica su orientación a mediados del siglo XIX para convertirse en una ciencia formal y es en este momento cuando pretende diferenciarse de los valiosos y extensos precedentes al colocarles la etiqueta de precientíficos (Palerm 2010a [1974]: 14).

3. Una historia de la antropología, concebida como el resultado de un proceso acumulativo de experiencias, descripciones y controversias, que se enmarcan históricamente en procesos de conquista, exploración, comercio y otras formas de movilidad durante dos milenios y medio, no puede ser reducida, como lo hacen los historiadores de la antropología anglosajones y franceses, a un corto periodo que arranca a finales del siglo XVIII, sin tener en cuenta toda la historia intelectual anterior, que se remonta a los autores clásicos grecorromanos. Una historia así es rechazada por Palerm, por su etnocentrismo y por su ideología imperialista (Peña 1987: 285).

Esta concepción a la vez humanista, crítica, universalista y postcolonial está en el centro de su concepción del papel que ha de jugar la antropología, entendida como comunidad científica. Pero una comunidad científica donde la producción en lengua española debe tener un mayor protagonismo, enlazando la tradición española, expresada en las aportaciones de los cronistas de Indias, y su construcción de la alteridad cultural con las nuevas tradiciones representadas por las ciencias sociales y humanas de raíz latinoamericana.

Si existe o puede existir una disciplina universal por su propia naturaleza, es la antropología. Si existe o puede existir un científico desprovisto de prejuicios nacionalistas, racistas, culturales o sociales, es el antropólogo. Formamos parte, profesores y estudiantes, de una verdadera comunidad internacional. Sin embargo, hay toda clase de razones - pedagógicas, académicas, culturales, hasta económicas- para desear ver una mayor producción en lengua española en el campo de la antropología sociocultural (Palerm 1967: 190).

Como afirma Jorge Alonso (2008) Palerm fue, antes que nada, un maestro de antropólogos. Murió prematuramente en Ciudad de México el 17 de junio de 1980. Hoy en día las decenas de discípulos que dejó repartidos por México en las principales instituciones que cultivan la práctica antropológica continúan su legado y guardan la memoria de quien fue su maestro.

${ }^{20}$ Este proyecto de una Historia de la Etnología vino precedido de un libro publicado en 1967, titulado Introducción a la Teoría Etnológica (Universidad Iberoamericana) (Palerm 1967). 


\section{OTROS EXILIADOS REPUBLICANOS ESPAÑOLES}

Se trata de Pedro Carrasco Pizana, José Luis Lorenzo Bautista, Enrique Nalda Hernández y Carmen Viqueira Landa. Haremos una presentación sucinta de su perfil y de su obra.

Pedro Carrasco Pizana nació en Madrid el año 1921, era hijo del físico español Pedro Carrasco Garronera, director del Observatorio Astronómico de Madrid, hasta su exilio. El joven Carrasco estudió en la ENAH y fue el segundo antropólogo graduado en México y el primero dentro de la especialidad de Etnohistoria. El año 1945 presentó su tesis de grado, titulada Cultura e historia prebispánica de los pueblos mesoamericanos de habla otomiana que, con el tiempo, se ha convertido en una obra clásica de la antropología mexicana (Carrasco 1950). Los conflictos surgidos entre él y el influyente arqueólogo mexicano Alfonso Caso le obligaron (como fue también el caso de Pedro Armillas y Ángel Palerm) a buscar alternativas para realizar su tesis doctoral. Se fue a Estados Unidos para hacer el doc-

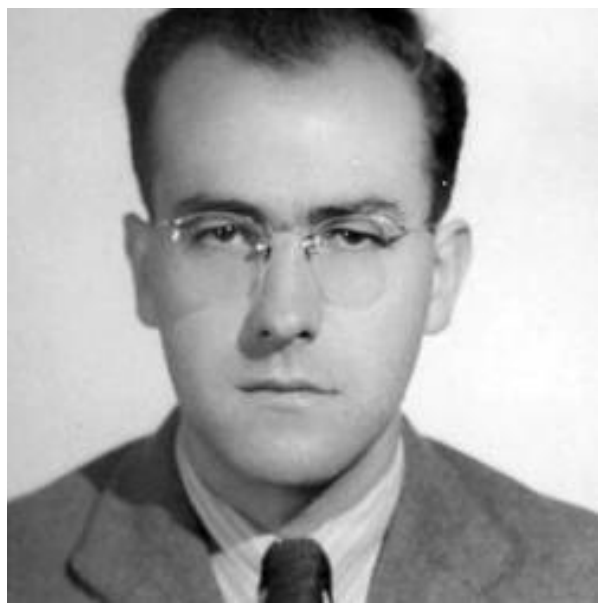

Pedro Carrasco (1951). Fuente: John Simon Guggenheim Memorial Foundation. Disponible en: <http://www.gf.org/fellows/all-fellows/pedrocarrasco-pizana/>. Fecha de acceso: 3 oct. 2017. torado en la Universidad de Columbia, tras obtener en 1951 una beca Guggenheim que le permitió acabar su doctorado en el año 1954 con una tesis titulada: Tarascan Folk Religion: An analysis of Economic, Social, and Religious Interactions. La tesis fue dirigida por el Prof. Ralph L. Beals, con quien ya había publicado un artículo conjunto en el año 1944 (Beals, Carrasco y McCorkie 1944).

Empezó su carrera académica en Brandeis University, pasando a la State University of New York (Stony Brook), donde hizo el resto de su carrera académica y donde era profesor emérito en el momento de su muerte en el año 2012. Pese a su segundo exilio a los EUA, a Carrasco se le debe considerar a todos los efectos como antropólogo mexicano por el mantenimiento de sus vínculos académicos y personales con el resto de colegas de la academia mexicana, así como por su incansable tarea de profundizar en el conocimiento del pasado prehispánico de México. Se especializó en el estudio del pueblo tarasco o purépecha (Carrasco 1976b), un gran imperio en la época precolonial que contenía otros pueblos, como los otomíes (Carrasco 1950) o los chichimeca (Carrasco 1963), pese a dedicar atención al Imperio Azteca (Carrasco 1974). Es autor o colaborador de numerosas obras colectivas de investigación o de divulgación del periodo anterior a la conquista (Carrasco 1976a, 1989, 1994 y 1999; Carrasco y Broda 1978; Carrasco y Gorostiza 2006).

José Luis Lorenzo Bautista nació, igual que Carrasco, el año 1921. Se formó en el Instituto Escuela de Madrid, una institución que proporcionaba una formación liberal y laica, impregnada por el movimiento krausista. En México hizo la formación prepa- 
ratoria para acceder a los estudios superiores. El año 1945 se incorporó a la ENAH donde tuvo una amplia gama de profesores, entre los adscritos a la propia ENAH más el profesorado visitante norteamericano. Con todo, su verdadero maestro en arqueología fue Pedro Armillas, pese a que este aún no había acabado sus estudios. También fue alumno de la etnóloga Isabel Kelly con la que estudió la comunidad indígena de El Tajín en Veracruz. Sus estudios de postgrado fueron realizados en Gran Bretaña, Francia y Suiza. Se especializó en estudios paleo-ambientales y en la geología del Cuaternario (Lorenzo 1958), adoptando una visión social de la arqueología, aplicada a la interpretación histórica de las revoluciones neolítica y urbana (Lorenzo 1961).

Junto a su actividad académica como profesor de la ENAH, dedicó una parte importante de su vida a la actividad museológica: Museo Nacional de Antropología, Museo de Antropología e Historia de Morelia (Michoacán), Museo de los Fuertes de Puebla. Su dedicación a la docencia, de la que fue un gran innovador y generador de una escuela de reputación internacional, junto con sus tareas de arqueólogo de campo y de gestor de lugares arqueológicos y museográficos, lo llevaron a una relevante tarea de divulgador y de sintetizador de la historia y la prehistoria en México (Lorenzo 1967, 1976, 1980 y 1982).

Enrique Nalda Hernández, nacido en Logroño en 1936, hijo de un funcionario de Hacienda en la etapa republicana, llegó a México a mediados de los años 40, siguiendo el exilio del padre, acompañado de su abuela paterna y hermana, tras la muerte de su madre. Se formó como ingeniero (UNAM) y antropólogo (ENAH), obteniendo su doctorado en Arqueología por la UNAM. El maestro que más influyó en su orientación investigadora fue Pedro Armillas. Fue durante décadas investigador de la Dirección de Estudios Arqueológicos del INAH, así como reconocido docente de la ENAH hasta 1984. Entre 1985 y 1986 fue coordinador nacional de centros del INAH. Junto con Javier López Camacho impulsó en esos años el proyecto de Atlas Arqueológico Nacional.

De su densa y reconocida labor investigadora destacan dos períodos diferenciados. El primero (1976-1984) centra sus investigaciones en San Juan del Río (Querétaro) (Nalda 1975), en el área del Lerma Medio (Nalda 1986) y en Morelos (Nalda 1987 y 1997). La segunda etapa, que se extiende desde 1986 hasta su defunción en 2010, se consagra íntegramente al estudio de la región maya, especialmente en el Estado de Quintana Roo, donde destacan sus excavaciones y trabajos de interpretación de los lugares arqueológicos de Kohunlich, Dzibanché e Ichkabal (Nalda, Campaña y López 1994; Nalda y Velázquez 2000; Nalda 1998, 2004 y En prensa).

Carmen Viqueira Landa, nacida en Badajoz el 20 de agosto de 1923, de familia gallega, vivió la mayor parte de su vida hasta la Guerra Civil en Madrid, donde estudió en el Instituto Escuela (1926-1933) y en el Instituto Velázquez (1934-1939). Llegó a México con su familia en 1940, después de pasar un año en Inglaterra, acogida por una familia británica. Hizo los estudios preparatorios en el Colegio Hispano-mexicano y en seguida conoció a Ángel Palerm con quién se casó. Estudió Psicología en la UNAM. En las comunidades de El Tajín y Eloxochitlán, donde Ángel Palerm trabajaba junto con Isabel Kelly, Viqueira aplicó tests psicológicos, que dieron como resultado una publicación conjunta (Viqueira y Palerm 1951). Su tesis doctoral, dirigida por Stanley Diamond (1977), fue Percepción y Cultura, donde desarrolló sus tesis sobre fundamen- 
tos culturales de la percepción: el carácter adaptativo al medio geográfico y climático para el desarrollo de las capacidades sensoriales humanas, en oposición a las teorías innatistas (Melville 2011: 166).

La trayectoria académica de Carmen Viqueira está estrechamente ligada a los ritmos y etapas de la trayectoria de su marido. La etapa de Ángel Palerm en la OEA (1954-1967) fue el periodo en el que Viqueira pudo realizar su tesis doctoral. Regresados a México, contribuyó en cuerpo y alma a la consolidación del Programa de Antropología de la Universidad Iberoamericana, creado por Palerm. Desde 1978 fue la Directora del Departamento de Antropología de esta Universidad, cuando Palerm fue designado director del CIS-INAH, futuro CIESAS. En este periodo, que llega hasta su jubilación, publica dos trabajos principales (Viqueira y Urquiola 1990; Viqueira 2001) y se dedica principalmente a reeditar algunos de los trabajos de su marido. Todos los biógrafos de Viqueira destacan su dedicación constante a la mejora del programa de postgrado en Antropología de la Ibero, actividad que continuó desarrollando, incluso jubilada. Moría en Ciudad de México el día 21 de julio de 2010.

\section{LA GENERACIÓN DE LOS HIJOS DE LOS EXILIADOS EN LA ANTROPOLOGÍA MEXICANA}

Los antropólogos de la segunda generación está compuesta por Gloria Artís Espriu, Gloria Artís Mercadet, Armando Bartra Vergés, Roger Bartra i Murià, Andrés Fábregas Puig, Jordi Gussinyer Alfonso, Jacinta Palerm Viqueira y Juan V. Palerm Viqueira. Haremos una muy breve caracterización de todos ellos.

Gloria Artís Espriu, hija de Arcadi Artís y Maria Teresa Espriu, hoy jubilada, fue profesora-investigadora en CIESAS, sede México DF. Tanto su licenciatura como su maestría en Antropología las obtuvo en la Universidad Iberoamericana. Su ámbito de especialización es la Etnohistoria y su línea de investigación prioritaria es el análisis de las relaciones sociales en la etapa de la restauración borbónica de Nueva España. Entre sus publicaciones destaca su estudio de la oligarquía novohispana (Artís Espriu 1994), un estudio sobre el mercado del trigo en la Ciudad de México del siglo XVIII (Artís Espriu 1986), la propiedad de la tierra (Artís Espriu 1991) y el sistema de minifundio (Artís Espriu 1997), así como la organización del trabajo (Artís Espriu 1992).

Glòria Artís Mercadet, hija de Avel·lí Artís (Tisner) y de Lluïsa Mercadet, se graduó en la ENAH en la especialidad de arqueología. Es miembro de la Academia Mexicana de Ciencias Antropológicas y, hasta el año 2009, fue coordinadora nacional de antropología del INAH. Forma parte del sistema de investigadores y dirige la revista Diario de campo. Aparte de sus publicaciones especializadas dentro del ámbito de la arqueología, ha hecho una importante tarea divulgativa, publicando o coordinando libros como Antropología e Historia (Artís Mercader 2000), La antropología en su lugar (Artís Mercader 2004) o ¿A qué nos referimos cuando hablamos de Antropología? (Artís Mercader 2013).

Armando Bartra Vergés, hijo de Carles Bartra y Daniela Vergés, nació en Ciudad de México. Realizó estudios de Filosofía en la UNAM, donde se graduó en 1966. Actualmente es profesor-investigador en el Departamento de Relaciones Sociales, de la UAM-Xochimilco. Aunque su actividad principal es la de activista y ensayis- 
ta, posee una dilatada trayectoria como docente: profesor en la licenciatura de Antropología (ENAH, 1977-1982), en la Maestría de Antropología (ENAH, 1990-1994). Entre 1974 y 2007 ocupó sucesivamente los cargos de subdirector y director del Centro de Estudios para el Desarrollo Rural Maya. Sus líneas de investigación han sido los estudios agrarios y regionales y los movimientos campesinos. En 2011 recibió el doctorado bonoris causa por la Universidad de Córdoba (Argentina). Su obra escrita tiene un cariz eminentemente divulgativo, con habituales colaboraciones en la prensa, junto a más de 30 libros de ensayo muy divulgados, entre ellos (Bartra 1996, 2000, 2006, 2010 y 2013).

Roger Bartra i Murià, hijo de Agustí Bartra y Anna Murià, nació en Ciudad de México el 7 de noviembre de 1942. Se formó en Etnología en la ENAH y en Sociología en la Universidad de la Sorbona, donde obtuvo el grado de doctor. Fue profesor e investigador del Instituto de Investigaciones Sociales de la UNAM. Ha sido profesor visitante en diferentes universidades, Universidad Pompeu Fabra de Barcelona, Centro Paul Getty de Los Ángeles, Universidad de Wisconsin, Universidad de California La Jolla y en la Cátedra Joaquim Xirau de la Universidad de Barcelona (2010). Actualmente es investigador emérito de la UNAM. Entre su veintena larga de libros debemos destacar: La jaula de la melancolía (Bartra i Murià 1987), El salvaje en el espejo (Bartra i Murià 1992), Oficio mexicano (Bartra i Murià 1993), La fractura mexicana (Bartra i Murià 2009), El mito del salvaje (Bartra i Murià 2011) y La sombra del futuro (Bartra i Murià 2012).

Andrés A. Fábregas Puig, hijo de exilado catalán y madre descendiente de catalanes afincados en México, nació en Tuxtla Gutiérrez, Chiapas, el 14 de febrero de 1945. En 1969 obtuvo el Máster en Etnología, sección de Etnohistoria de la ENAH, con una tesis sobre Nahualismo y su expresión en la región de Chalco-Amecameca. El año 1970 accedió al doctorado de la UIA, que incorporaba una estancia de un año en la Universidad de Nueva York, Stony Brook. Su tesis fue leída, bajo la supervisión de Ángel Palerm, en CIESAS. Se inició en la docencia en la UIA, fundó, junto con José Lameiras, Juan Vicente Palerm y Roberto Varela, el Departamento de Antropología de la UAMIztapalapa. Allí permaneció como profesor hasta 1985. Ha sido profesor en más de diez universidades mexicanas y extranjeras. Fundador y primer Rector de la Universidad de Ciencias y Artes de Chiapas y de la Universidad Intercultural de Chiapas. Durante su estancia en Guadalajara (Jalisco) fundó el programa de doctorado en ciencias sociales de El Colegio de Jalisco. Actualmente es profesor-investigador de CIESAS Occidente. Como investigador ha hecho importantes aportaciones a la antropología social y, desde el punto de vista regional, destacan sus publicaciones dedicadas a Chiapas (Fábregas 2010-2011 y 2012) y a Jalisco (Fábregas 1986), así como un estudio muy reconocido sobre el fútbol (Fábregas 2000) y un trabajo comparativo entre los Altos de Jalisco y la Sierra de Ávila, en colaboración con Pedro Tomé (Tomé y Fábregas 2000 y 2002; Fábregas y Tomé 2001).

Jordi Gussinyer Alfonso, hijo de un médico de Banyoles (Girona), militante de ERC, se exiló junto a su familia a México tras la Guerra Civil. Realizó estudios de Arquitectura y, posteriormente, de Arqueología en la UNAM. Se especializó en arqueología maya y trabajó esencialmente en Chiapas. A mediados de los años 70 volvió a Barcelona, incorporándose al departamento de Antropología Cultural e Historia de América de la Universidad de Barcelona el curso 1979-1980. Su extensa obra se orienta al estudio 
de la arquitectura religiosa, tanto indígena como colonial, en el área maya (Gussinyer 1992, 1996, 2004, 2005 y 2008).

Jacinta Palerm Viqueira, hija de Ángel Palerm y de Carmen Viqueira, se licenció en Antropología en la UIA y realizó sus estudios de posgrado en Geografía Humana en la Universidad de Toulouse-Le Mirail. Sus líneas de especialización son los estudios campesinos, las organizaciones agrarias y los procesos de innovación tecnológica. Ejerce de profesora e investigadora en el Colegio de Posgraduados, Campus Montecillo, donde dicta cursos sobre la organización social campesina, la problemática del pequeño riego en México y las organizaciones campesinas autogestionadas. Ha sido directora de numerosas tesis de maestría y de doctorado. Entre sus publicaciones destacan sus trabajos sobre el riego y las formas de organización social en que se enmarcan (Palerm Viqueira, Jacinta 1995, 2005 y 2006), así como otros trabajos en colaboración con María Giménez (Palerm Viqueira, Jacinta y Giménez 2007), Carlos Chairez (Palerm Viqueira, Jacinta y Chairez 2002) y María Rivas (Palerm Viqueira, Jacinta y Rivas 2005). En 1997 publicó en Nueva Antropología un trabajo muy relevante sobre el papel del trabajo de campo en la formación de los jóvenes investigadores (Palerm Viqueira, Jacinta 1997).

Juan Vicente Palerm Viqueira, hijo también de Ángel Palerm y de Carmen Viqueira, es profesor emérito en la Universidad de California Santa Barbara (UCSB). Recibió el título de doctor en Antropología Social por la Universidad Iberoamericana (1983) y fue miembro fundador del Departamento de Antropología Social de la Universidad Autónoma Metropolitana-Iztapalapa (1975). Ocupó la dirección del Center for Chicano Studies de UCSB (1984-1994), la dirección del University of California Institute for Mexico and the United States, UC MEXUS (1994-2003) y fundó La Casa de la Universidad de California en México. Se dedica al estudio del surgimiento de una nueva sociedad rural en California, resultado de la reestructuración de la agroindustria y de la sedentarización masiva de trabajadores agrícolas en California procedentes de México.

Nacido en Estados Unidos, y tras cursar los estudios secundarios, se trasladó a Madrid, donde cursó Estudios Hispánicos en la Universidad Complutense (1964-1966). Posteriormente cursó la licenciatura en Filosofía y Letras, especializándose en Antropología y Etnología de América, en la misma universidad (1966-1971). Entre 1971 y 1974 fue profesor ayudante de Antropología en la UCM, siendo el gran impulsor de la incorporación de la etnografía en la formación de los estudiantes. Fue el creador y editor de los Cuadernos de Antropología Social y Etnología (1971-1973), revista dirigida a los estudiantes de orientación monográfica. Entre 1975 y 1978 realizó sus estudios de maestría en CIESAS y en 1983 defendió su tesis doctoral en la UIA con el tema de Los nuevos campesinos. En 1984 se trasladó a California (Santa Bárbara) donde desarrolló el resto de su carrera académica.

La orientación investigadora del Prof. Palerm ha estado siempre vinculada al campesinado mexicano. Su orientación durante más de veinte años ha sido estudiar las migraciones campesinas mexicanas hacia los Estados Unidos (Palerm Viqueira, Juan V. 1991, 1992, 1997a, 1997b y 1999). Ha contribuido de manera destacada en dos grandes obras que conectan sus intereses con las de otros investigadores. Es, pues, coautor, junto a F. Suberví-Vélez, del Handbook of community-based organizations serving Latinos in selected sites in California (Palerm Viqueira, Juan V. y Suberví-Vélez 1992). Fue coeditor, junto a Devra Weber y Roberto Melville, de la recuperación de una im- 
portante colección de entrevistas realizadas por Manuel Gamio entre 1926 y 1927 a inmigrantes mexicanos (Palerm Viqueira, Juan V., Weber y Melville 2001) ${ }^{21}$.

Existe una tercera generación, de la que solamente conocemos el caso de Diana Negrín, nieta de Juan Negrín, último presidente del gobierno de la República. Formada en Geografía en la Universidad de California, Berkeley, es actualmente investigadora postdoctoral en CIESAS. Está especializada en estudios mexicanos, estudios raciales y culturales y en la economía política de la urbanización. Defendió su tesis doctoral en Berkeley el año 2014: Colores Mexicanos: Racial Alterity and the Right to the Mexican City.

\section{LA COMUNIDAD MEXICANO-CATALANA DE ANTROPÓLOGOS Y ANTROPÓLOGAS: RAÍCES Y MEMORIA}

Los exilios, otros exilios, están también presentes en esta genealogía intelectual, que enmarca la memoria que hemos ido construyendo sobre nuestros orígenes. Debemos nombrar a la figura, ya citada en el inicio de este texto, de Josep María Batista $i$ Roca. Entre 1915 y 1916 residió en Londres y Oxford, dedicándose a la etnología. Fue uno de los fundadores el año 1917 del Arxiu d'Etnografía i Folklore de Catalunya, junto con Tomás Carreras y Artau. Fue uno de los introductores del excursionismo en Cataluña y en 1927 organizó los Minyons de Muntanya. Se exilió a Inglaterra y desde 1939 a 1976, fecha de su retorno a Cataluña, fue profesor del Trinity College de Cambridge, reorientando su carrera hacia la historia. Fue un gran activista de la cuestión catalana, siendo uno de los principales promotores del Consell Nacional Català. En el año 1978, en que se creó el Institut Català d'Antropologia, Batista i Roca fue nombrado presidente honorífico, intentando simbólicamente hacer el enlace entre aquella tradición de estudios etnológicos de inicios del siglo XX, de la que él fue pionero, con el relevo que protagonizaba nuestra generación.

El exilio también está presente, en sentido opuesto, con la llegada a mediados de los años 1970 de la Dra. Dolores Juliano, casada con un emigrante catalán afincado en Argentina, país del que se tuvo que exiliar a causa de la dictadura militar. Desde 1977 fue profesora del Departamento de Antropología de la Universidad de Barcelona, hasta su jubilación, acaecida el año 2001. Especialista en antropología de la educación, estudios de género, migraciones e identidades étnicas, ha dedicado también una buena parte de su obra a analizar diferentes formas de exclusión social. El año 2010 recibió la Creu de Sant Jordi, en reconocimiento a sus aportaciones científicas y cívicas.

Un colega de Juliano en la Universidad de Mar de Plata en el momento de la llegada de la dictadura a la Argentina era Eduardo Menéndez Spina. Él optó por el exilio a México, donde se convirtió en una figura de referencia dentro del ámbito de la antropología médica. Sus estudios sobre el alcoholismo le otorgaron prestigio internacional. Además de sus aportaciones a este campo de especialización, ha hecho con-

\footnotetext{
${ }^{21}$ Dentro de esta misma segunda generación, debemos destacar la existencia de varias antropólogas, hijas o nietas de inmigrantes españoles Dra. Carmen Icazuriaga (investigadora en CIESAS, hija de vasco), las Dras. Virginia García (investigadora de CIESAS), Carmen Bueno (profesora de la de la UIA) y Marisol Pérez (también de la UIA), todas ellas con ancestros asturianos.
} 
tribuciones fundamentales en el campo de la teoría y la epistemología antropológicas. Desde hace más de 25 años Menéndez ha contribuido con su magisterio a la consolidación del campo de la antropología médica en la universidad Rovira i Virgili. Como testimonio de reconocimiento por su labor el día 21 de mayo de 2009 fue investido doctor honoris causa por la URV ${ }^{22}$.

Aunque no se trata de exilios, el vigor de las ciencias antropológicas mexicanas mantiene su capacidad de atracción para las nuevas generaciones nacidas en Cataluña. Son varios los académicos catalanes que se han afincado en México en los últimos 25 años. Tal es el caso del arqueólogo Josep Ligorred Perramon (Manlleu, 1963), quien en 1981 se trasladó a Ciudad de México para estudiar el grado de arqueología (ENAH, 1988). Desde hace más de 20 años reside en Mérida, habiendo sido jefe del Departamento de Patrimonio Arqueológico y Natural del Ayuntamiento de Mérida (19992010). Cursó sus estudios de maestría en la UADY. En 2013 obtuvo el doctorado por la Universidad de Barcelona, siendo su tesis publicada posteriormente, La gestión de los sitios arqueológicos en áreas urbanas del estado de Yucatán, México (Ligorred 2013). La Dra. María Isabel Campos Goenaga llegó a México un año más tarde, en 1982, vinculándose desde el primer momento a la ENAH, primero como estudiante y más tarde como docente y gestora de cargos académicos. Allí se doctoró en la especialidad de Etnohistoria. Tras ser subdirectora académica de CIESAS (2012-2015), actualmente es coordinadora nacional de Antropología del INAH. Su línea preferente de investigación aborda la cuestión de los desastres naturales y la construcción social del riesgo y de la vulnerabilidad. Sus investigaciones se han centrado en Yucatán (Campos 2011 y 2014). Un tercer ejemplo de esta migración académica reciente desde Cataluña hacia México es la Miguel Lisbona Guillén, quien tras licenciarse en la Universidad de Barcelona en las especialidades de Historia Moderna y Antropología Social (1990), marchó a México a cursar en la UAM-Iztapalapa su maestría (1994) y doctorado (2000). Sus investigaciones se han centrado en la región de Chiapas, siendo autor de numerosas publicaciones en las que aborda las relaciones de poder, simbólicas y religiosas. Su libro, en coautoría, Diversidad religiosa y conflicto en Chiapas: intereses, utopías y realidades (Rivera Farfán et al. 2011) obtuvo el premio Fray Bernardino de Sahagún, otorgado por el INAH. Fue uno de los fundadores de la Universidad de Ciencias y Artes de Chiapas, donde fue profesor.

Mi reconstrucción de los hilos argumentales y personales que fundamentan nuestra identidad colectiva profesional y generacional, a pesar de ser amplia, no agota ni de lejos todos los vínculos que nos unen a los exilios y, en especial, al exilio republicano. Se trata, sin duda, de una reconstrucción subjetiva, que el tiempo y la crítica de mis compañeros generacionales acabarán de depurar y de fijar. Como decía Halbwachs, "la historia no es todo pasado, pero tampoco es todo lo que queda del pasado. $\mathrm{O}$, si se quiere, junto a una historia escrita, se encuentra una historia viva que se perpetua o se renueva a través del tiempo" (Halbwachs 2011: 209).

\footnotetext{
${ }^{22}$ Por no alargar más este texto panorámico, ya de por sí bastante largo, no abordo otra cuestión central, que deberá abordarse en el futuro desde la perspectiva de las rupturas intelectuales que supuso la irrupción de la dictadura franquista. Me refiero a los exilios interiores. Sin duda, en este apartado la figura más destacada es la del antropólogo vasco Julio Caro Baroja, cuya inmensa obra no ha recibido la suficiente atención.
} 
En otras palabras, queda claro que resulta muy difícil separar aquello que es memoria histórica de lo que es memoria colectiva. Tiene razón Pierre Nora cuando afirma que "el estallido de la memoria es la culminación de su desaparición en el fuego de la historia. La necesidad de memoria es una necesidad de historia" (Nora 1984). Pero en el caso que nos ocupa, las cosas, quizás, son un poco diferentes. La historiografía sobre Guerra Civil, sobre franquismo y sobre exilio republicano es abrumadoramente amplia. Los historiadores han hecho (y creo que han hecho bien) su trabajo. Pero la historia no puede suplir la ausencia de políticas públicas que restauren la memoria de los vencidos, de los republicanos, de los exiliados. El derecho a la memoria es el derecho a la recuperación de la dignidad, una dignidad pisada durante más de ochenta años. La historia y los historiadores no pueden suplantar el pacto de silencio con que se inició la transición política hacia la democracia. Los abusos y la crueldad de los vencedores durante medio siglo no han tenido ninguna reparación simbólica. Los alemanes pidieron perdón por el genocidio nazi. El sector franquista de la sociedad española no solamente no ha pedido perdón, sino que parece estar muy orgulloso de este largo periodo de la historia. La España rota es la España indigna de los que se aprovecharon de la otra media España. Unos sufriendo el silencio y el miedo dentro de un exilio interior. Los otros esforzándose por volver a casa, refugiados en muchos lugares del mundo gracias a la acogida forzada o generosa de países de tres continentes.

México, sin duda, constituye un caso singular. Desde muchos puntos de vista se convirtió en la verdadera patria de los apátridas, expulsados de su casa para ser fieles a la legalidad vigente y a sus ideas de progreso. Algunos volvieron, otros permanecieron por siempre más en esa tierra de promisión. México no es, no puede ser, un país extranjero para todos nosotros. México, como argumentó Gaos, es la encarnación en muchos sentidos de aquello que hubiera podido ser la patria ibérica. Las trayectorias de esta docena y media larga de colegas y maestros que acabamos de evocar, pese al trauma y al duelo por la pérdida que supuso su exilio, se acercan a aquello que hubiera podido ser la vida normal de unos intelectuales de primer orden, que fueron suplantados por una generación mediocre salida al calor de la dictadura franquista. México es para todos nosotros un lugar central de la memoria y los exiliados republicanos que hemos adoptado como ancestros de nuestra estirpe son los monumentos de esta memoria, un patrimonio colectivo de todos nosotros, que abastece nuestra identidad y nuestra línea de filiación.

En esta labor de recuperación de la memoria colectiva y, en particular, en el trabajo de ver las conexiones, estímulos, continuidades y discontinuidades entre el legado intelectual de nuestros exilados y el panorama español de las ciencias antropológicas, es mucho lo que queda por hacer. En estas páginas que aquí se presentan, solamente he pretendido nombrar a los principales protagonistas de esta historia de transterración, queda ahora una labor de mayor aliento, más selectiva, de análisis de los impactos y recepciones que su importante labor docente e investigadora han generado en esta España que quiere ir recuperando su memoria. 


\section{BIBLIOGRAFÍA CITADA}

Abellán, José L. 2001. El exilio como constante y como categoría. Madrid: Biblioteca Nueva.

Alonso, Jorge. 2008. Ángel Palerm Vich. Serie Biografías, 1. México: Colegio de Etnólogos y Antropólogos Sociales.

Alonso, María. 1979. Archivo de la palabra. Entrevistas al doctor Ángel Palerm Vich. México: Dirección de Estudios Históricos/Instituto Nacional de Antropología e Historia.

Meyer, Eugenia (coord.) 1980. Palabras del exilio 1. Contribución a la bistoria de los refugiados españoles en México. México: INAH/SEP/Librería Madero.

Alonso, María y Marta Baranda. 1984. Palabras del exilio 3. Seis antropólogos mexicanos. México: INAH/SEP/Librería Madero.

Armillas, Pedro. 1948. "A sequence of cultural development in Mesoamerica. A Reappraisal of Peruvian Archaeology". Memoirs of the Societv for American Archaeology 4: 105-111.

Armillas, Pedro. 1949. "Notas sobre sistemas de cultivo en Mesoamérica: cultivos de riego y humedad en la cuenca del Río de las Balsas". Anales del Instituto Nacional de Antropología e Historia III: $85-113$.

Armillas, Pedro. 1951. "Tecnología, formaciones socio-económicas y religión en Mesoamérica", en The Civilizations of Ancient America. Selected Papers of the XXIXth International Congress of Americanists: 19-30. Chicago: The University of Chicago Press.

Armillas, Pedro. 1966. "Los orígenes del cultivo en el Nuevo Mundo: antecedentes y procesos de desarrollo", en Actas y Memorias del XXXVI Congreso Internacional de Americanistas, vol. 1: 17580. Sevilla: ECESA.

Armillas, Pedro. 1975. "Archaeological Survey of the Barbarian Frontier of the Aztec Empire", en American Philosophical Society Year Book, 1974: 561-563. Filadelfia: American Philosophical Society.

Artís, Avel-lí. 1972. Al cap de vint-i-sis anys. Barcelona: Ed. Pòrtic.

Artís, Avel-lí. 1974. Els vençuts. Barcelona: Eds. 62.

Artís, Avel-lí. 1989-1996. Viure i veure, 4 vols. Barcelona: Ed. Pòrtic.

Artís Espriu, Glòria. 1986. Regatones y maquileros. El mercado de trigo en la Ciudad de México en el siglo XVIII. México: CIESAS.

Artís Espriu, Glòria. 1991. "La tierra y sus dueños: Chalco durante el siglo XVIII", en Alejandro Tortolero (coord.), Entre lagos y volcanes. Chalco Amecameca: pasado y presente: 197-225. México: El Colegio Mexiquense/Ayuntamiento constitucional de Chalco.

Artís Espriu, Glòria. 1992. "La organización del trabajo en los molinos de trigo (siglo XIX)", en Glòria Artís et al., Trabajo y sociedad en la historia de México: siglos XVI-XVIII. México: Centro de Investigaciones y Estudios Superiores en Antropología Social.

Artís Espriu, Glòria. 1994. Familia, riqueza y poder. Un estudio genealógico de la oligarquía novohispana. México: CIESAS.

Artís Espriu, Glòria. 1997. "Minifundio y fraccionamiento de la tierra ejidal parcelada". Revista de Estudios Agrarios 3(8): 11-32.

Artís Mercadet, Glòria 2000. Antropología e Historia. México: CONACULTA.

Artís Mercadet, Glòria 2004. La antropología en su lugar. México: INAH.

Artís Mercadet, Glòria 2013. ¿A qué nos referimos cuando hablamos de Antropología? México: INAH. Aub, Max 2008. Escritos sobre el exilio. Manuel Aznar (ed.). Sevilla: Ed. Renacimiento.

Bartra, Armando. 1996. Guerrero bronco. Campesinos, ciudadanos y guerrilleros en la Costa Grande. México: Eds. Sin Filtro.

Bartra, Armando. 2000. Crónicas del sur. Utopías campesinas en Guerrero. México: Era.

Bartra, Armando. 2006. El capital en su laberinto. De la renta de la tierra a la renta de la vida. México: Itaca/UACM.

Bartra, Armando. 2010. Campesindios. Aproximaciones a los campesinos de un continente colonizado. La Paz: CIDES/Universidad Mayor de San Marcos.

Bartra, Armando. 2013. El hombre de hierro: los limites sociales y naturales del capital en la perspectiva de la gran crisis. México: UAM-Xochimilco.

Bartra i Murià, Roger. 1987. La jaula de la melancolía. México: Grijalbo. 
Bartra i Murià, Roger. 1992. El salvaje en el espejo. México: Era/UNAM.

Bartra i Murià, Roger. 1993. Oficio mexicano: miserias y esplendores de la cultura. Grijalbo: México. Bartra i Murià, Roger. 2009. La fractura mexicana: izquierda y derecha en la transición mexicana. México: Random House Mondadori.

Bartra i Murià, Roger. 2011. El mito del salvaje. México: FCE.

Bartra i Murià, Roger. 2012. La sombra del futuro. Reflexiones sobre la transición mexicana. México: FCE.

Beals, Ralph L., Pedro Carrasco y Thomas McCorkle. 1944. Houses and bouse use of the sierra Tarascans. Washington: Smithsonian Institution/Institute of Social Anthropology.

Bernecker, Walther L. 2011. "Los estudios sobre el exilio republicano en México", en Andrea Pagni (ed.), El exilio republicano español en México y Argentina: 33-57. Madrid: Iberoamericana.

Bladé, Artur. 1976. L'exiliada. Dietari de l'exili (1939-1940). Barcelona: Ed. Pòrtic.

Bladé, Artur. 1993. De l'exili a Mèxic. Barcelona: Curial.

Bonfil, Guillermo. 1993. Simbiosis de culturas. Los inmigrantes y su cultura en México. México: CONACULTA.

Bosch i Gimpera, Pere. 1919. Prehistòria catalana: edats de la pedra i dels metalls, colonització grega, etnografia. Barcelona: Editorial Catalana.

Bosch i Gimpera, Pere. 1928. La razas bumanas. Barcelona: Institut Gallach.

Bosch i Gimpera, Pere. 1929. El estado actual de la investigación de la cultura ibérica. Madrid: Tipografía de Archivos.

Bosch i Gimpera, Pere. 1932. Etnología de la Península Ibérica. Barcelona: Alpha.

Bosch i Gimpera, Pere. 1938. L'art grec a Catalunya. Barcelona: ADAC.

Bosch i Gimpera, Pere. 1944. El poblamiento antiguo y la formación de los pueblos de España. México: Imprenta Universitaria.

Bosch i Gimpera, Pere. 1945. El hombre primitivo y su cultura. México: SEP.

Bosch i Gimpera, Pere. 1946. Història de Catalunya. México: Catalònia.

Bosch i Gimpera, Pere. 1980. Memòries. Barcelona: Edicions 62.

Bosch i Gimpera, Pere. 1981. El problema de las Españas. México: UNAM.

Brufau, Joana, María Permanyer y Xavier Zulet. 2011. "Entrevista a Claudio Esteva Fabregat, antropólogo". Periferia 14: 1-32.

Buñuel, Luís. 1982. Mi último suspiro. México: Ed. Plaza y Janés.

Calders, Pere. 1964. L'ombra de l'atzavara. Barcelona: Selecta.

Calvo, Lluís. 1991. El Arxiu d'Etnografia i Folklore de Catalunya y la antropología catalana. Barcelona: CSIC.

Calvo, Lluís. 1994. Tomàs Carreras i Artau o el tremp de l'etnologia catalana. Barcelona: Eds. De l'Abadia de Montserrat.

Calvo, Lluís. 1996. "Claudio Esteva, Ethnica y la antropología", en Joan Prat y Ángel Martínez (eds.), Ensayos de antropología cultural. Homenaje a Claudio Esteva Fabregat: 42-49. Barcelona: Ariel.

Calvo, Lluís. 1997. Historia de la antropología en Cataluña. Barcelona: CSIC.

Campos Goenega, M. ${ }^{a}$ Isabel. 2011. Entre crisis de subsistencia y crisis colonial: La sociedad yucateca y los desastres en la coyuntura 1765-1774. México: INAH-CONACULTA.

Campos Goenega, M. ${ }^{a}$ Isabel. 2014. La llama divina. Nueva mirada a los procesos e informaciones sobre idolatrías en Yucatán (1552-1562). México: Eds. del Lirio/Casal Català del Yucatán.

Carrasco, Pedro. 1950. Los otomies. Cultura e bistoria prebispánica de los pueblos mesoamericanos de habla otomiana. México: UNAM-ENAH.

Carrasco, Pedro. 1963. "Los caciques chichimecas de Tulancingo". Estudios de Cultura Nabuatl 4: $85-91$

Carrasco, Pedro. 1974. "Sucesión y alianzas matrimoniales en la dinastía teotihuacana". Estudios de cultura Nabuatl 9: 235-242.

Carrasco, Pedro. 1976a. "Los linajes nobles del México Antiguo. Estratificación social en la Mesoamérica Prehispánica", en Pedro Carrasco y Johanna Broda (eds.), Estratificación social en la América Prebispánica: 19-36. México: CIS-INAH.

Carrasco, Pedro. 1976b. El catolicismo popular de los tarascos. México: SepSetentas.

Carrasco, Pedro. 1989. "Los mayeques". Historia Mexicana 39(1): 123-166. 
Carrasco, Pedro. 1994. "La sociedad mexicana antes de la conquista", en Historia General de México, vol. 1: 231-287. México: El Colegio de México.

Carrasco, Pedro. 1999. The Tenochca Empire of Ancient Mexico: The Triple Alliance of Tenochtitlan, Tetzcoco, and Tlacopan. Norman, Ok: University of Oklahoma Press.

Carrasco, Pedro y Johanna Broda (eds.). 1978. Economía politica e ideología en el México prebispánico. México: Nueva Imagen.

Carrasco, Pedro y J. Gorostiza. 2006. Estructura Politico-territorial del Imperio Tenochca. La Triple Alianza de Tenochtitlan, Tetzcoco y Tlacopan. México: FCE.

Comas Camps, Joan. 1946. Las razas humanas. México: Biblioteca Enciclopédica Popular.

Comas Camps, Joan. 1966. Manual de antropología física. México: Fondo de Cultura Económica.

Comas Camps, Joan. 1959. Paleoantropología y evolución. Cuadernos del Instituto de Historia, Serie Antropológica, núm. 6. México: UNAM.

Comas Camps, Joan. 1960. La antropología física en México, 1943-1959. Cuadernos del Instituto de Historia, Serie Antropológica, núm. 10; en colaboración con Santiago Genovés. México: UNAM.

Comas Camps, Joan. 1967. Unidad y variedad de la especie bumana. México: Dirección General de Difusión Cultural.

Comas Camps, Joan. 1971. Introducción a la prebistoria general. México: Imprenta Universitaria.

Comas Camps, Joan. 1972. Razas y racismo. México: Septetentas.

Comas Camps, Joan. 1979. "Bibliografía del profesor Juan Comas Camps". Revista Española de Antropología Americana IX: 61-73.

Contreras, Jesús, Joan J. Pujadas y Ignasi Terradas. 2000. "Ángel Palerm y los antropólogos españoles del 68", en Virginia García-Acosta (ed.), La diversidad intelectual. Ángel Palerm, in memoriam: 43-61. México: CIESAS.

El exilio español en México, 1939-1982. 1982. México: FCE.

Enríquez, Alberto. 1990. México y España: solidaridad y exilio político, 1936-1942. México: Secretaría de Relaciones Exteriores.

Enríquez, Alberto. 2004. Ayuda a los republicanos españoles. Correspondencia entre Alfonso Reyes y José Puche, 1939-1940. México: El Colegio Nacional.

Fábregas, Andrés. 1986. La formación histórica de una región. Los Altos de Jalisco. México: CIESAS.

Fábregas, Andrés. 1992. "Una visión del desarrollo de la Antropología en México", Anuario 1991 del Instituto Chiapaneco de Cultura: 11-22. Tuxtla Gutiérrez: Instituto Chiapaneco de las Culturas. Disponible en: <http://repositorio.cesmeca.mx/handle/cesmeca/231>. Fecha de acceso: 20 oct. 2015 .

Fábregas, Andrés. 2000. Lo Sagrado del Rebaño. El futbol como integrador de identidades. Zapopán: El Colegio de Jalisco.

Fábregas, Andrés. 2010-2011. Configuraciones Regionales Mexicanas. Un planteamiento antropológico, 2 vols. México: Gobierno de Tabasco/Universidad Intercultural de Chiapas.

Fábregas, Andrés. 2012. El mosaico chiapaneco: etnografía de las culturas indigenas. México: Comisión Nacional para el Desarrollo de los Pueblos Indígenas.

Fábregas, Andrés y Pedro Tomé. 2001. Entre Parientes. Zapopan: El Colegio de Jalisco-Diputación de Ávila.

Fagen, Patricia. 1975. Transterrados y ciudadanos: los republicanos españoles en México. México: FCE.

Gaos, José. 1947. "Los "transterrados" españoles de la filosofía en México". Filosofía y Letras 36: 207-231.

Gaos, José. 1966. "La adaptación de un español a la sociedad hispanoamericana". Revista de Occidente 38: 168-178.

Genovés, Santiago. 1956. A study of sex differences in the innominate bone (os coxae), with special reference to the material from St. Bride's Church. Londres: E. C. I. Cambridge/Universidad de Cambridge.

Genovés, Santiago. 1958. "Estudio de los restos óseos de Coixtlahuaca, Estado de Oaxaca, México", en Miscelanea Paul Rivet, vol. 1: 455-484. México: UNAM.

Genovés, Santiago. 1960. "Revaluation of age, stature and sex of the Tepexpan remains, Mexico". American Journal of Physical Anthropology 18: 205-218. 
Genovés, Santiago. 1965. "Problemas relativos al origen del hombre en América". Anales de Antropología 2: 121-129.

Genovés, Santiago. 1966. "Racismo". Revista de la Sociedad Venezolana de Sociología 12: 10-32.

Genovés, Santiago. 1967. "Proportionality of the long bones and their relation to stature in Mesoamericans". American Journal of Physical Anthropology 26: 67-78.

Genovés, Santiago. 1974. ¿Por qué Acali? Barcelona: Promoción Cultural S.L.

Genovés, Santiago. 1975. Acali. Barcelona: Planeta.

Genovés, Santiago. 1976. El mono inquisitivo: convivencia y comportamiento humano. Barcelona: Planeta. Genovés, Santiago. 1986. "La primera declaración sobre la Violencia". Boletín de la Asociación Mexicana de Antropología Biológica 4: 17-18.

Genovés, Santiago y D. Richard Bainbridge. 1956. "A study of sex differences in the scapula, with special reference to the material from St. Bride's Church, London, E. C. I.", Journal of the Royal Anthropological Institute of Great Britain and Ireland 86(2): 109-134.

Genovés, Santiago y Joan Comas. 1964. La antropología física en México, 1943-1964. Inventario y programas de investigaciones. Cuadernos del Instituto de Investigaciones Históricas, Serie Antropológica 17. México: UNAM.

Gili, Mario. 1970. La década bárbara. México: Imprenta Madero.

Giral, Francisco. 1994. Ciencia española en el exilio (1939-1989). Barcelona: Ed. Anthropos/CIERE.

Gussinyer, Jordi. 1992. "Notas para el concepto de espacio en la arquitectura precolombina de mesoamérica". Boletín americanista 42: 183-230.

Gussinyer, Jordi. 1996. "Los inicios de la arquitectura cristiana en el nuevo mundo", en Pilar García Jordán (coord.), Las raíces de la memoria. América Latina, ayer y hoy. Quinto Encuentro Debate: 57-82. Barcelona: Servei de Publicacions de la UB.

Gussinyer, Jordi. 2005. "Ciudades y centros ceremoniales: una aproximación al urbanismo de Mesoamérica". Boletín americanista 55: 123-148.

Gussinyer, Jordi. 2008. "Mesoamerica y el urbanismo del siglo XVI cristiano: la plaza indoeuropea". Boletín Americanista 58: 229-250.

Gussinyer, Jordi y Juan García Targa. 2004. "Los primeros templos cristianos en el áreas maya: Yucatán y Belice, 1545-1585". Estudios de Cultura Maya XXV: 95-119.

Halbwachs, Maurice. 2011. La memoria colectiva. Buenos Aires: Ed. Miño y Ávila.

Kelly, Isabel y Ángel Palerm. 1952. The Tajin Totonac, vol. 1. Subsistence, Shelter, and Technology. Washington: Smithsonian Institution.

León-Portilla, Ascensión Hernández de. 1978. España desde México. Vida y testimonio de transterrados. México: UNAM.

Lida, Clara. 1988. La Casa de España en México. México: El Colegio de México.

Lida, Clara (ed.). 1994. Una inmigración privilegiada. Comerciantes, empresarios y profesionales españoles en México en los siglos XIX y XX. Madrid: Alianza Ed.

Lida, Clara. 1997. Inmigración y exilio. Reflexiones sobre el caso español. México: Ed. Siglo XXI.

Lida, Clara. 2009. "Lázaro Cárdenas frente a la Guerra Civil española", en Clara Lida (ed.), Caleidoscopio del exilio. Actores, memoria, identidades: 131-141. México: El Colegio de México.

Lida, Clara. 2011. "Un exilio en vilo", en Andrea Pagni (ed.), El exilio republicano español en México y Argentina: 21-32. Madrid: Iberoamericana.

Lida, Clara y José A. Matesanz. 2000. El Colegio de México. Una hazaña cultural, 1940-1962. México: El Colegio de México.

Ligorred, Josep. 2013. La gestión de los sitios arqueológicos en áreas urbanas del estado de Yucatán, México. Barcelona: Universidad de Barcelona.

Rivera Farfán, Carolina, María del Carmen García Aguilar, Miguel Lisbona Guillén, Irene Sánchez Franco, Salvador Meza Díaz. 2011. Diversidad religiosa y conflicto en Chiapas. Intereses, utopías $y$ realidades. México: CEM/PROIMMSE/UNAM/CIESAS.

Llobera, Josep R. 1975. La Antropología como ciencia. Barcelona, Anagrama.

Lorenzo, José L. 1958. Los glaciares de México. Monografía n.ํㅜ 1. México: Instituto de Geofísica de la UNAM.

Lorenzo, José L. 1961. La revolución neolitica en Mesoamérica. México; INAH.

Lorenzo, José L. 1967. La etapa lítica de México. México: INAH. 
Lorenzo, José L. 1976. "Los orígenes mexicanos", en Historia General de México, vol. 1: 83-123. México: El Colegio de México.

Lorenzo, José L. 1980. "De la polémica sobre arqueología”. Revista de Historia Americana 90: $103-118$.

Lorenzo, José L. 1982. "Práctica y teoría del salvamento arqueológico", en Rex L. Wilson y Gloria Loyola (eds.), Arqueología de rescate: 158-177. Washington: Fondo Nacional para la Preservación Histórica/OEA/The Preservation Press.

Martí, Miquel. 1989. L'orfé Català de Mèxic, 1906-1986. Barcelona: Curial.

Martínez, Carlos. 1959. Crónica de una emigración, la de los republicanos españoles en 1939. México: Libro Mex Eds.

Matesanz, José A. 1978. México y la República española. Antología de documentos, 1931-1977. México: Centro Republicano Español de México.

Matesanz, José A. 2000. Las raíces del exilio. México ante la Guerra Civil española, 1936-1939. México: El Colegio de México.

Nalda, Enrique. 1975. San Juan del Río: trabajos arqueológicos preliminares. Tesis de maestría. México: ENAH-INAH.

Nalda, Enrique. 1986. "Descripción y evaluación de un muestreo de área en el Lerma Medio". Revista Mexicana de Estudios Antropológicos XXXII: 79-105.

Nalda, Enrique. 1987. "El desarrollo de las investigaciones arqueológicas en Morelos", en Zonas Arqueológicas de Morelos. Mecanoescrito. [S.1.]: [s. n.].

Nalda, Enrique. 1997. "El noroeste de Morelos y la desestabilización teotihuacana". Arqueologia 18: 103-117.

Nalda, Enrique. 1998. "La arqueología del sur de Quintana Roo: los problemas por resolver y los enfoques por adoptar", en Memorias del Tercer Congreso Internacional de Mayistas: 743-751. México: UNAM.

Nalda, Enrique. 2004. Kobunlich: su emplazamiento y desarrollo bistórico. México: INAH.

Nalda, Enrique. En prensa. Dzibanché, su entorno y las exploraciones arqueológicas. Panorámicas arqueológicas: ayer y hoy. Manuscrito de 2005. México: Grupo Azabache.

Nalda, Enrique, L. E. Campaña y J. López Camacho. 1994. "Sur de Quintana Roo: Dzibanché y Kinichná". Arqueología Mexicana II(10): 14-19.

Nalda, Enrique y Adriana Velázquez. 2000. "Kohunlich: mitos y reflexiones sobre su historia prehispánica", en Adriana Velázquez (ed.), Guardianes del tiempo: 15-35. México: Universidad de Quintana Roo/Conaculta/INAH.

Nora, Pierre. 1984. Les lieux de la mémoire. París: Gallimard.

Pagni, Andrea (ed.) 2011. El exilio republicano español en México y Argentina. Historia cultural, instituciones literarias, medios. Madrid: Iberoamericana.

Palerm, Ángel. 1967. Introducción a la Teoría Etnológica. México: UIA.

Palerm, Ángel. 1973. Obras hidráulicas prebispánicas en el sistema lacustre del Valle de México. México: SEPINAH.

Palerm, Ángel. 1976. Modos de producción y formaciones socioeconómicas. México: EDICOL.

Palerm, Ángel. 1980. Antropología y marxismo. México: Nueva Imagen/CIS-INAH.

Palerm, Ángel. 2005 [1976]. Historia de la etnología. Los evolucionistas. México: UIA/ITESO.

Palerm, Ángel. 2010a [1974]. Historia de la etnología. Los precursores. México: CIESAS/UIA.

Palerm, Ángel. 2010b [1977]. Historia de la etnología. Tylor y los profesionales británicos. México: CIESAS/UIA.

Palerm, Ángel y Eric Wolf. 1972. Agricultura y civilización en Mesoamerica. México: SEP/Colección Sepsetentas.

Palerm Viqueira, Jacinta. 1995. "Sistemas hidráulicos y organización social: la polémica y los sistemas de riego del Acolhuacan septentrional". Mexican Studies/Estudios Mexicanos 11(2): 163-178.

Palerm Viqueira, Jacinta. 1997. "El trabajo de campo y la formación de investigadores". Nueva Antropología XV(51): 133-143.

Palerm Viqueira, Jacinta. 2005. "Gobierno y administración de sistemas de riego: tipologías". Región y Sociedad XVII(34): 3-33.

Palerm Viqueira, Jacinta. 2006. "Self-Management of Irrigation Systems, a Typology: The Mexican Case”. Mexican Studies/Estudios Mexicanos 22(2): 361-385. 
Palerm Viqueira, Jacinta y María Giménez. 2007. "Organizaciones tradicionales de gestión del agua: importancia de su reconocimiento legal como motor de supervivencia". Región y SociedadXIX (38): 3-24.

Palerm Viqueira, Jacinta y Carlos Chairez. 2002. "Medidas antiguas de agua". Relaciones. Estudios de bistoria y sociedad XXIII(92): 227-251.

Palerm Viqueira, Jacinta y María Rivas. 2005. "Organización social y riego". Nueva Antropología XIX(64): 9-29.

Palerm Viqueira, Juan V. 1991. Farm Labor Needs and Farm Workers in California, 1970 to 1989. California Agricultural Studies 91-92. Sacramento: Employment Development Department.

Palerm Viqueira, Juan V. 1992. "A Binational System of Agricultural Production: The Case of the Mexican Bajio and California", en Daniel G. Aldrich y Lorenzo Meyer (eds.), Mexico and the United States: Neighbours in Crisis. San Bernadino: Borgo Press.

Palerm Viqueira, Juan V. 1997a. The expansion of California agriculture and the rise of peasantworker communities. Riverside: University of California.

Palerm Viqueira, Juan V. 1997b. Immigrant and migrant farm workers in the Santa Maria Valley, California. Santa Barbara: Center for Chicano Studies, University of California.

Palerm Viqueira, Juan V. 1999. "Las nuevas comunidades mexicanas en los espacios rurales de los Estados Unidos de América: a propósito de una reflexión acerca del quehacer antropológico". Áreas. Revista de ciencias sociales 19: 153-180.

Palerm Viqueira, Juan V. y Federico A. Suberví-Vélez. 1992. Handbook of community-based organizations serving Latinos in selected sites in California. Berkeley: California Policy Seminar, University of California.

Palerm Viqueira, Juan V., Devra Weber y Roberto Melville (eds.). 2001. Manuel Gamio. El inmigrante mexicano, la bistoria de su vida, entrevistas completas, 1926-1927. México: Ed. Porrúa.

Palma, Mónica. 2006. De tierras extrañas. Un estudio sobre la inmigración en México, 1950-1990. México: SEGOB.

Peña, Guillermo de la. 1987. "Orden social y educación en México: la pervivencia de un legado colonial", en Susana Glantz (ed.), La heterodoxia recuperada. En torno a Ángel Palerm: 285-320. México: FCE.

Peyrí, Antoni. 1953. Els metges catalans emigrats. México: Club del Llibre Català.

Pla, Dolores. 1985. Los niños de Morelia. Un estudio sobre los primeros refugiados españoles en México. México: INAH.

Pla, Dolores. 1994. "Características del exilio en México en 1939", en Clara Lida (ed.), Una inmigración privilegiada. Comerciantes empresarios y profesionales españoles en México en los siglos XIX y XX: 218-231. Madrid: Alianza.

Pla, Dolores. 2000. Els exiliats catalans. Un estudi de la immigració republicana. Catarroja: Ed. Afers.

Pla, Dolores. 2007. Pan, trabajo y hogar. El exilio republicano español en América Latina. México: Instituto Nacional de Migración/INAH.

Pla, Dolores, Guadalupe Zárate, Monica Palma, Jorge Gómez, Rosario Cardiel y Delia Salazar. 1993. Extranjeros en México (1821-1990). Bibliografía. México: INAH.

Pla, Dolores, María Magdalena Ordoñez Alonso y Teresa Férriz Roure. 1997. El exilio catalán en México. Notas para un estudio. Jalisco: El Colegio de Jalisco.

Prat Carós, Joan. 1980. "Els estudis etnogràfics i etnològics a Catalunya”. Quaderns de l'ICA 1: $30-63$.

Prat Carós, Joan. (ed.). 1986. "Trenta anys de literatura antropològica sobre Espanya". Arxiu d'Etnografia de Catalunya 4-5: 1-226.

Prat Carós, Joan. 1990. "Folklore, cultura popular i nacionalisme a Catalunya (1853-1936)". Cultura 8: 32-34.

Prat Carós, Joan. 1991. "Du folklore a l'ethnologie dans les revues catalanes (1862-1984)", en JeanPierre Piniès, Christiane Amiel y René Piniès (eds.), Au miroir des revues. Ethnologie de l'Europe $d u$ Sud: 117-137. Cahiers d'Ethnologie Méditerranéenne 1. Carcassonne: Garae/Hesiode.

Prat Carós, Joan (ed.). 1999. "Investigadores e investigados: Literatura antropológica en España desde 1954". Arxiu d'Etnografia de Catalunya (edición especial): 1-551.

Prat Carós, Joan y Joan J. Pujadas. 1991. "Nouvelles perspectives", en Jean-Pierre Piniès, Christiane Amiel y René Piniès (eds.), Au miroir des revues. Ethnologie de l'Europe du Sud: 139-143. Cahiers d'Ethnologie Méditerranéenne 1. Carcassonne: Garae/Hesiode. 
Prats, Llorenç, M. ${ }^{a}$ Dolors Llopart y Joan Prat. 1982. La cultura popular a Catalunya. Estudiosos $i$ institucions (1853-1981). Barcelona: Fundació Serveis de Cultura Popular.

Pujadas, Joan J. 1980. "Breu esbós de la vida i obra de Josep Maria Batista i Roca amb motiu de la seva mort". Quaderns de l'ICA 1: 99-111.

Pujadas, Joan J. 1984. "Cap a una antropologia de les societats complexes: apunts metodològics", en Neus Escandell y Ignasi Terradas (eds.), Història i Antropologia. A la memòria d'Àngel Palerm: 265-276. Barcelona: Abadia de Montserrat.

Pujadas, Joan J. 2000. "La recuperació de la memòria col·lectiva: reflexions metodològiques sobre Guerra Civil i franquisme», en Narcís Figueras y Antoni Reyes (eds.), Guerra Civil i franquisme. Seixanta anys després: 33-47. Figueres: Centre d'Estudis Selvatans.

Pujadas, Joan J. 2014. "Historia de la Etnología de Ángel Palerm: humanismo y criticismo al servicio de una visión poscolonial de la antropología". Descatos 45: 149-153.

Pujadas, Joan J. y Joan Prat. 1981a. "Spanish Anthropology: a Selected Bibliograpahy I". Bulletin of the Society for Spanish and Portuguese Historial Studies 6(1): 39-47.

Pujadas, Joan J. y Joan Prat. 1981b. "Spanish Anthropology: a Selected Bibliograpahy II". Bulletin of the Society for Spanish and Portuguese Historial Studies 6(2): 73-90.

Santos, Yaiza. 2009. "Claudio Esteva Fabregat, antropólogo y pasajero del Sinaia", Letras Libres 9 setiembre. México. Disponible en: <http://www.letraslibres.com/blogs/claudio-esteva-fabregatantropologo-y-pasajero-del-sinaia>. Fecha de acceso: 25 oct. 2015.

Somolines d'Ardois, Germán. 1966. 25 años de medicina española en México. México: Ateneo Español de México.

Tomé, Pedro y Andrés Fábregas. 2000. Entre Mundos. Zapopan: El Colegio de Jalisco-Diputación de Ávila.

Tomé, Pedro y Andrés Fábregas. 2002. Regiones y Fronteras. Zapopan: El Colegio de Jalisco.

Viqueira, Carmen. 2001. El enfoque regional en Antropología. México: Universidad Iberoamericana.

Viqueira, Carmen y Ángel Palerm. 1951. "Alcoholismo, brujería y homicidio en dos comunidades rurales de México". América Indigena XIX(1): 7-36.

Viqueira, Carmen y José I. Urquiola. 1990. Los obrajes en la Nueva España 1530-1630. México: CONACULTA.

Fecha de recepción: 4 de agosto de 2016

Fecha de aceptación: 8 de marzo de 2017 